\title{
When a Nudge Backfires: Using Observation with Social and Economic Incentives to Promote Pro-Social Behavior
}

\author{
Gary Bolton ${ }^{1}$, Eugen Dimant ${ }^{2}$, Ulrich Schmidt ${ }^{3}$ \\ ${ }^{1}$ University of Texas at Dallas \\ ${ }^{2}$ University of Pennsylvania \\ ${ }^{3}$ Kiel Institute for the World Economy
}

Most recent version of the paper always available here

\begin{abstract}
Both theory and recent empirical evidence on nudging suggests that observability of behavior acts as an instrument for promoting (discouraging) pro-social (anti-social) behavior. Our study questions the universality of these claims. We employ a novel four-party setup to disentangle the roles three observational mechanisms play in mediating behavior. We systematically vary the observability of one's actions by others as well as the (non-)monetary relationship between observer and observee. Observability involving economic incentives crowds-out anti-social behavior in favor of more pro-social behavior. Surprisingly, social observation without economic incentives fails to achieve any aggregate pro-social effect, and if anything it backfires. Additional experiments confirm that observability without additional monetary incentives can indeed backfire. However, they also show that the effect of observability on pro-social behavior is increased when social norms are made salient.
\end{abstract}

Keywords: Anti-Social Behavior, Experiment, Nudge, Pro-Social Behavior, Reputation JEL: C91, D64, D9

${ }^{*}$ This work benefited from discussions with Anastasia Danilov, Christine Exley, Jana Freundt, Judd Kessler, Katherine Milkman, Muriel Niederle, Al Roth, and Silvia Sonderegger. We also thank participants at the 2018 Norms and Behavioral Change Workshop, as well as seminar participants at the Kiel Institute for the World Economy, the Lab@DC Behavioral Research Team, and Yale University for helpful feedback. Financial support from the German Science Foundation (DFG) through the research unit "Design Behavior" (FOR 1371) is gratefully acknowledged.

Email addresses: gbolton@utdallas.edu (Gary Bolton), edimant@sas.upenn.edu (Eugen Dimant, corresponding author), Ulrich.Schmidt@ifw-kiel.de (Ulrich Schmidt) 


\section{Introduction}

Much of the existing behaviorally informed policies have focused on improving individual and collective well-being, with some approaches having yielded more success than others (Thaler and Sunstein, 2008; Benartzi et al., 2017; Brandon et al., 2017). Importantly, however, much less scholarly attention has been paid to the unintended and sometimes detrimental consequences of nudging (Reijula et al., 2018), which go beyond simply unsuccessful interventions, but may lead to actual backfiring effects that worsen outcomes. ${ }^{1} \mathrm{~A}$ few recent examples of backfires that resulted from nudge interventions include an increase in energy consumption (Ayres et al., 2013), reduced savings in a 401(k) (Beshears et al., 2015), an increase in prescription of antibiotics (Hallsworth et al., 2016), and a decline in sustainable food choices (Richter et al., 2018). These studies are important because they highlight the potential risks of behavioral interventions that are being used to affect societal and economic outcomes on both the individual and collective level (Madrian, 2014).

Our paper adds to this growing body of alarming results by presenting the backfiring of a particular prominent nudge: increasing observability of behavior to induce pro-sociality. While the impact of observability on inducing pro-social behavior can be exerted through various mechanisms such as reputation concerns, shame, and feelings of increased accountability (Ernest-Jones et al., 2011; Ekström, 2012; Rogers et al., 2018), existing literature reveals mixed results and a distorted picture of when and why certain nudges that capitalize on observation and harness reputation (do not) work. We attempt to shed more light on these conflicting results in a controlled environment by disentangling the several behavioral channels at play. We achieve this by varying observability of one's actions by others as well as the (non-)monetary relationship between observer and observee in a controlled laboratory setup. We employ the following design: A decision maker can donate money from her own account to a charity or can transfer money from the charitys account to her own. In the baseline treatment, the only player who can observe the decision maker's action is the decision maker herself (the self-image treatment). We complement the baseline with two observability treatments. In one treatment (social image condition, SocSig), an unin-

\footnotetext{
${ }^{1}$ Given the methodological difficulty of comparing nudge interventions (Szaszi et al., 2018), which is amplified by inherent publication bias of null-findings in social sciences, it is challenging to credibly estimate how many nudge interventions fail. Anecdotal evidence suggest that up to $50 \%$ of the interventions fail, as argued by David Laibson in his talk at the Wharton Business School on November 12, 2018. The number is based on his personal - and likely positively biased - scholarly experience.
} 
volved third party observes the decisions of the dictator. In another condition (reputation treatment, Reputation), decisions are observed by a person the dictator interacts with in a later stage of the game. This is precisely a situation of indirect reciprocity as a better social image may lead to future benefits in this treatment.

More generally, we can think of social observation as a nudge intended to get people to think about the social consequences of their behavior, usually with the aim of encouraging pro-social behavior or reducing anti-social behavior. ${ }^{2}$ This has become a particularly popular approach in the current 'nudge revolution' due to its fairly frugal implementation.

Beyond tit-for-tat reputation mechanisms, the empirical relation between observability and social behavior is less clear and has produced conflicting evidence, which we try to reconcile in our experiment. Studies analyzing the effect of observability on pro-sociality find a variety of results ranging from positive (Haley and Fessler, 2005; Lacetera and Macis, 2010), to negative effects (Lambarraa and Riener, 2015), to no effect (Dufwenberg and Muren, 2006; Matland and Murray, 2016), in particular when the observer is an uninvolved third party (Alpízar and Martinsson, 2013; Festré and Garrouste, 2015). In contrast, evidence suggests that there is a strong effect of observability if the observer interacts with the giver in later rounds of the game, i.e. during which (monetary) reputation concerns are present (Bradley et al., 2018). Importantly, however, and in the spirit of our investigation, recent evidence has produced the insight that observation can backfire under certain circumstances; i.e., if it is viewed as coercive. Exemplary, past charity donors, who were reminded by email to donate, were observed to do so at first but then observed to remove themselves from the mailing list. This is evidence to suggest that a reminder, in the form of observation, created resistance on the part of the donors (Damgaard and Gravert, 2018). Other research that has considered the effects of observability on anti-social behavior finds that observing and being observed can lead to, in particular, behavioral contagion of anti-social behavior and erosion of norms (Falk and Fischbacher, 2002; Gino et al., 2009; Dimant, 2018; Bicchieri et al., 2018a; Rilke et al., 2018).

In contrast to this literature, we are not investigating how observation of others' behavior affects one's own behavior. Instead, we are interested in answering: how does the exposure of one's actions affect one's decisions to engage in pro- or anti-social behavior?

\footnotetext{
${ }^{2}$ Here we will equate pro-social behavior with actions that increase the welfare of others and anti-social behavior with actions that decrease the welfare of others. See Dimant (2018) for a discussion in a similar context.
} 
Our aim is to disentangle the mechanisms through which observability of behavior nudges behavior. In particular, we focus on the prominent channels of altruism/self-image, social image, and the reputation mechanism. We systematically vary the degree of observability of one's actions and the degree to which the parties interact with each other. Typically, experimental analyses of indirect reciprocity involve dictator games where only a giving option is present (within the context of reputation concerns in charitable giving see, e.g., Kajackaite and Sliwka, 2017). In contrast to the this and much of the related nudging literature more generally that addresses the role of observability, we employ a framework where both pro- and anti-social behavior is simultaneously possible. For this purpose, we refine the give-or-take dictator game setting (List, 2007; Bardsley, 2008) and augment the setup with a charity and other (un)involved parties. ${ }^{3}$ Therefore, our design allows us to study the impact of an observability nudge in a indirect reciprocity setting where anti-social behavior is possible as well (see also Balliet et al. 2014).

It is worthwhile putting this more recent stream of literature in perspective. A central finding in behavioral economics is that people display pro-social behavior, at least under certain institutional conditions, i.e. when compliant (deviant) behavior can be enforced in both monetary and non-monetary terms (Becker, 1968; Xiao and Houser, 2011; Cooper and Kagel, 2016; Bicchieri et al., 2018b). Observability is also the basis for institutionalized reputation mechanisms, which leverage economic incentives and have been shown to facilitate social welfare enhancing outcomes such as increasing coordination and trust and enabling trade relations (Buchan et al., 2002; Bolton et al., 2004, 2013). Also, indirect reciprocity (Alexander, 1987; Nowak and Sigmund, 1998a,b; Grimalda et al., 2016), a major explanation for the evolution of human cooperation, relies on the reputation gained from observable previous actions. Crucial to the effectiveness of observability in these contexts is the possibility that the observer can reciprocate or enforce the behavior of the observee.

Historically, some of the most prominent evidence for pro-social behavior has been gathered from the dictator game (Forsythe et al., 1994), in which subjects may voluntarily transfer a substantial fraction of their own endowment to other individuals. From early

\footnotetext{
${ }^{3} \mathrm{~A}$ recent debate centers around the question whether giving in the dictator game can really be interpreted as intrinsic altruism or is either (i) an artifact of the experimental design (List, 2007; Bardsley, 2008) as people can only give but not take and, therefore, giving may be due to an experimenter demand effect or (ii) caused by the observability of decisions by other persons such that giving is due to social image concerns rather than due to intrinsic altruism (Dana et al., 2006, 2007; Andreoni and Bernheim, 2009; Lazear et al., 2012; Cappelen et al., 2017).
} 
on, a critical point of debate has been the role of observability as a catalyst for observed generosity. Specifically, whether pro-social behavior is driven by the economic consequences of the reputation that results from being observed, or whether the act of being observed is in itself a sufficient pro-social motive (Andreoni and Bernheim, 2009). ${ }^{4}$

Our results cast doubt on the universality and effectiveness of such a nudge. Similar to earlier studies, we find that reputation mechanisms that allow for a (monetary) enforcement component increase pro-social behavior and curtail anti-social behavior relative to the baseline in which the only observer is oneself. This shows that the evidence on reputation mechanisms and indirect reciprocity is robust with respect to a generalization of the experimental design where both pro- and antisocial behavior are possible. However, we also find that social observation, absent the tit-for-tat lever, has little effect on overall pro-social behavior and, if anything, indicates that anti-social behavior can increase.

We establish the robustness of this unexpected result in a second experiment on Amazon mTurk where we used a larger and more heterogeneous sample of participants (Snowberg and Yariv, 2018) to also investigate the potential mechanisms in more detail. There, we conducted a second experiment focusing on the self and social observation conditions and two variants thereof. For one, the experiment reproduces the results of our laboratory experiment and finds that mere observation can indeed yield significantly more pronounced anti-social behavior. For another, to narrow down the relevant mechanisms, this second experiment includes two additional treatments that capitalize on the approach of Cialdini et al. $(1990,1991)$ as instrumentalized by Krupka and Weber (2009) and study the role of norm focus in the context of our unexpected results. Using this approach, we test the hypothesis that nudging people to think about a descriptive norm of what others do affects the efficacy of the observation intervention. The nudge turns out to be highly effective. There is, in addition, a pro-social cross effect with social observation of roughly equal size.

In light of our findings, one of our main conclusions is that social observation per se has little pro-social benefit in a setting in which both anti-social and pro-social actions

\footnotetext{
${ }^{4}$ Arguably, social approval is a motivation so deeply ingrained in human nature that even when observers cannot reciprocate behavior through a reputation system, social observation might still act to nudge the observee's decision-making towards pro-social action (Akerlof, 1980; Andreoni and Bernheim, 2009; Lacetera and Macis, 2010). Absent observability, the act of giving in a dictator game can result from intrinsic altruism or the desire to maintain a positive self-image (Bénabou and Tirole, 2006; Hamman et al., 2010; Bénabou and Tirole, 2011; Falk and Tirole, 2016). One possible channel in this context is the well-known warm glow of giving (Andreoni, 1990).
} 
are attainable. Rather, in the absence of enforcement mechanisms, the power of social observation rests largely with its ability to nudge decision makers into making the existence and applicability of norms salient.

Our paper follows the following structure: Section 2 details the laboratory experiment and develops a theoretical foundation for the testable hypotheses. We conclude this section with discussion of the first set of results. The second experiment is discussed in detail in Section 3 and we conclude in Section 4.

\section{Experiment 1: Laboratory}

\subsection{Design}

Our basic design capitalizes on an extended one-shot dictator game with a taking option (most closely mirroring List, 2007; Bardsley, 2008; Dimant, 2018, but see also Coffman, 2011). Participants were randomly assigned to one of three roles (A, B, or C) that differ in their action space:

- Player A moves first and plays the role of a dictator who is assigned to a charity. Both player A and the charity start with an initial endowment of 100 ECU. ${ }^{5}$ Player A must decide whether to (i) give some or all of her own endowment to charity, (ii) not change the equal split, or (iii) take some or all of the charity's endowment and add this to her own endowment. ${ }^{6}$

- Player B moves second and plays the role of a dictator who is in charge of a cash box. Both Player B and the cash box have an initial endowment of 100 ECU. The final payoff of $\mathrm{B}$ is always equal $100 \mathrm{ECU}$ in that it is unaffected by any of her own or other players' decisions in the experiment. Player B must then decide whether to transfer any or all of the money from the cash box to Player A. Any amount left in the cash box will be returned to the experimenter. Hence, Player B has no personal monetary incentive for her actions, as she cannot enhance her own payoff by leaving money in the cash box. ${ }^{7}$

\footnotetext{
${ }^{5}$ The exchange rate used in the experiment was $10 \mathrm{ECU}=€ 1$.

${ }^{6}$ We include a welfare multiplier of 2 for giving decisions in that the experimenter will double every monetary unit transferred to the charity account.

${ }^{7}$ Again, we include a welfare multiplier so that the experimenter will double any amount given to Player A. This is necessary to give Player A the incentive to be rewarded by Player B and leave the experiment
} 
- Player $\mathrm{C}$ has the role of a passive observer who does not engage in active decisionmaking. Just as with Player B, Player C has an initial endowment and a final payoff of $100 \mathrm{ECU}$.

A crucial feature of our experimental design is that we systematically vary the observability of the decisions that participants make across treatments. Our experiment consists of one Baseline specification and two treatments. In the Baseline condition, henceforth referred to as SelfSig, Player A's behavior remains unobserved by other participants; any reputation concerns are absent and each decision is merely self-signaling. ${ }^{8}$ That is, Player B makes her decision without knowing what Player A did. Figure 1 displays the action space and the order of actions for all participants in this Baseline condition.
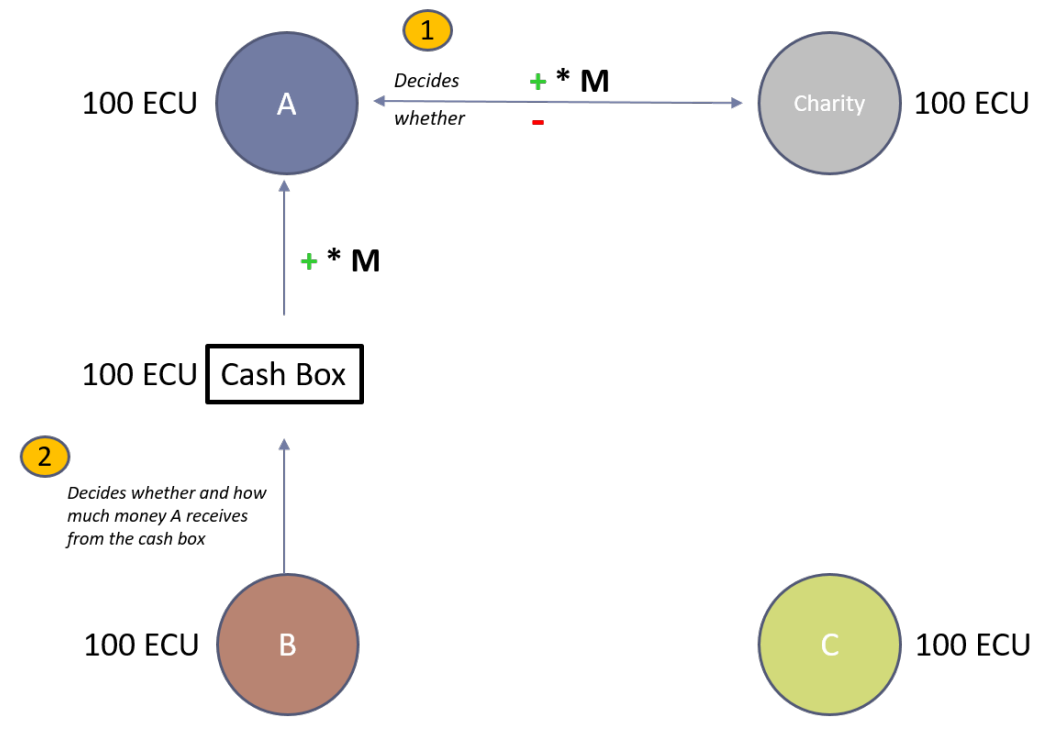

Figure 1: Experiment 1 - Baseline Condition (SelfSig).

with more money than she started with. For example, if Player A decides to give all of her money (100 ECU) to charity, this amount is then doubled and added to the charity account with the initial 100 ECU, making it a total of 300 ECU. If, in return, Player B decides to give all of the money (100 ECU) in the cash box to Player A, this amount is then doubled and Player A ends up with 200 ECU. In consequence, a fully pro-social behavior on the side of both Player A and Player B leads to a substantial welfare increase.

${ }^{8}$ Admittedly, self-signaling exists in all treatments. In this treatment, however, self-signaling is the exclusive channel. In line with the theoretical predictions, the extent of self-signaling is the same across treatments, and what varies are the additional channels such as reputation and social signaling. 
In Treatment 1, henceforth referred to as Reputation, Player B observes Player A's behavior, i.e. the amount given to or taken from the charity, before making her own decision about whether to give some or all of the money from the cash box to Player A. This is public knowledge and Player A is made aware of this circumstance prior to making her decision towards the charity. Therefore, both monetary and non-monetary concerns are at play as Player B can condition her cash box decision on Player A's behavior. We detail the mechanisms in Figure 2.

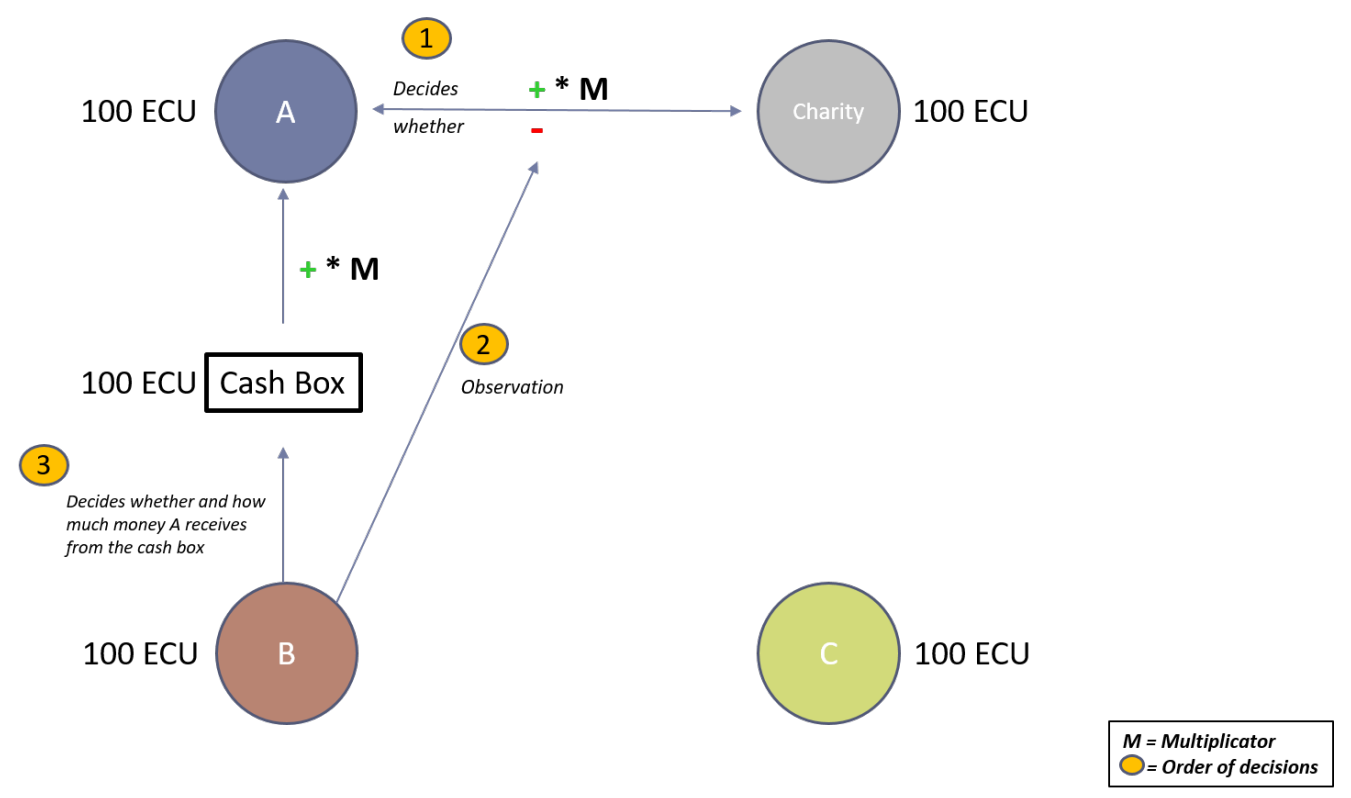

Figure 2: Experiment 1 - Treatment 1 (Reputation).

In Treatment 2, henceforth referred to as SocSig, Player C, rather than Player B, can observe the decision of Player A but has no impact on Player A's payoffs. Just as in the Baseline treatment, Player B makes her cash box decision without being informed about Player A's behavior. Hence, Player A's decision is being observed by a passive player which allows us to separate reputation concerns from social concerns. As was the case before, the setup is public knowledge and every player is made aware of the action space of each other player prior to the first decision being made. In consequence, in addition to self-signaling concerns that are existent in all treatments, Player A's behavior now also bears social signaling value. We present the details of this treatment in Figure 3.

The payoff structure employed in our experiment retains incentive compatibility while 


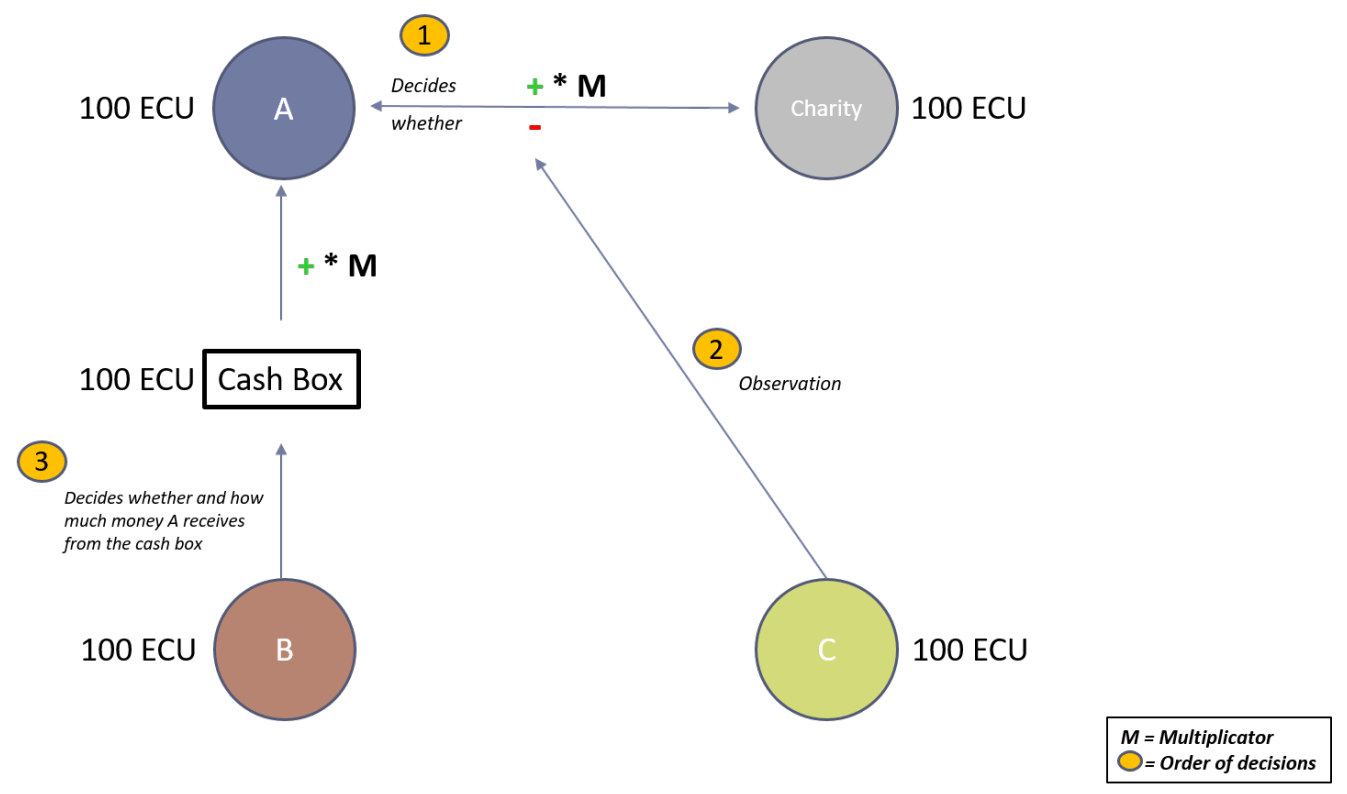

Figure 3: Experiment 1 - Treatment 2 (SocSig).

accounting for potential crowding out effects caused by strategic considerations. We achieve incentive compatibility by randomly selecting one group at the end of each session and then using the decisions of the group members to determine their own and the charity's payoffs. The payoff of the participants in the remaining $n-1$ groups is equal to their initial endowment (100 ECU), independent of their decisions throughout the experiment. ${ }^{9}$ The amount of the chosen charity payoff is then given randomly to one of the three pre-announced charities. This procedure is common knowledge among all participants and is explained in the instructions given on the participants' screens.

\subsection{Participants and Procedures}

Across three types of treatments, we recruited 423 subjects from various disciplines at the experimental laboratory at the University of Kiel, Germany. Participants were on average 24.6 years old and $54.7 \%$ were female. The experiment was programmed and conducted with z-Tree (Fischbacher, 2007). We ran a total of 28 sessions, each session lasting

\footnotetext{
${ }^{9}$ This implementation of a payoff function closely follows Bicchieri et al. (2018a) and Dimant (2018). This incentive scheme is in line with suggestions made by Charness et al. (2016) and retains incentive compatibility as theoretically argued by Azrieli et al. (2018).
} 
approximately 60 minutes. Upon arrival, subjects were randomly assigned to a computer. After the on-boarding process was completed, instructions were distributed and participants received sufficient time to read them carefully and to ask any clarifying questions. Each participant received the same basic instructions regardless of her role or treatment. Treatment variations were announced on the screen of the participants' computers. Once the experiment started, participants had to answer a series of comprehension questions to ensure the instructions were clearly understood. After each participant answered the questions correctly, the experiment continued with the random assignment of participants to roles. Depending on their assigned role, participants had to make decisions that simultaneously affected their own payoff and that of a charity, or that only affected the payoff of another participant, as indicated above. At the end of the experiment subjects filled out a questionnaire and were privately paid in cash according to the outcome of the experiment; the donation decision of one randomly selected participant was implemented. As a result, we donated a total of $€ 666.60$ to our three charities Doctors Without Borders, UNICEF, and WWF. See Table 1 for descriptive statistics.

\begin{tabular}{lccc}
\hline \hline & \multicolumn{3}{c}{ Treatments } \\
\cline { 2 - 4 } & SelfSig & Reputation & SocSig \\
\hline Participants & 138 & 138 & 147 \\
Female & $57 \%$ & $49 \%$ & $58 \%$ \\
Age (average) & 24.5 & 24.6 & 24.6 \\
\hline
\end{tabular}

Table 1: Descriptive Statistics. Total number of participants indicated. Because we employed triadmatching in our design, the indicated observations per treatment are evenly split between Players A, B, and C (41 per player type for both SelfSig and Reputation and 44 for SocSig).

\subsection{Theory and Behavioral Predictions}

Let us denote the money Player A transfers to the charity by $x$ where negative values of $x$ indicate taking money from the charity Due to Player A's initial balance we have $-100 \leq x \leq 100$. Thus, $100-x$ is the money Player A keeps in her private account. Additionally, Player A may receive money which Player B assigns to her from the cash box. We denote this transfer by $y$. We assume that the behavior of $\mathrm{A}$ is motivated by a combination of the following factors: 
1. Self-interest, i.e. the money kept from the initial endowment, the money taken from the charity (in total $100-\mathrm{x}$ ) and the expectations about the money Player B will transfer from the cash box $(y)$

2. Altruism, self-image and/or warm glow of giving, i.e. utility derived from transferring money to the charity ${ }^{10}$

3. The social image of A with respect to the observing player(s) $j\left(S I_{A, j}\right)$, which only comes into play if $x$ is observable by $j$.

Consequently, we get:

$$
U_{A}=U\left(100-x, x, E(y \mid x), S I_{A, j}(x)\right)
$$

For expositional purposes, we assume that the utility function is additively separable in its arguments (all results also hold for the general case):

$$
U_{A}=u(100-x)+v(x)+w(E(y \mid x))+S I_{A, j}(x)
$$

. where $u, v$, and $w$ are strictly increasing and $u$ is strictly concave. A central question in our design is the relation between $S I$ and $x$. When modeling $S I$, we follow Bursztyn and Jensen (2017) who refine the framework of Bénabou and Tirole (2006). Suppose there are two types of subjects, which we label altruistic $(a)$ and selfish $(s)$. Then $S I$ is given by

$$
S I_{A, j}(x)=\lambda_{A, j} E_{A}\left(\omega_{j}(a)\right) \operatorname{Prob}_{j}\left(\sigma_{A}=a \mid x\right)
$$

In this formulation $\operatorname{Prob}_{j}\left(\sigma_{A}=a \mid x\right)$ denotes the probability that $j$ thinks $A$ is of type $a$ given the observed value of $x . E_{A}\left(\omega_{j}(a)\right)$ gives A's expectations of the social desirability of being seen as type $a$ by group $j$ and, finally, $\lambda_{A, j}$ measures to which extent A cares about her image in group $j$.

Let us first consider the SelfSig treatment. In this treatment, no other player can

\footnotetext{
${ }^{10}$ Since the decisions from only Player A will be decisive for the payoff to the charity (due to the random selection used to counteract strategic considerations discussed previously), we cannot distinguish between altruism and self-image or a warm glow of giving. Such a distinction is, however, irrelevant for the focus of our paper.
} 
observe $x$. Thus, neither $y$ nor $S I$ are influenced by Player A's actions. The first-order condition (FOC) for optimal $x$ becomes

$$
u^{\prime}(100-x)=v^{\prime}(x)
$$

i.e., in the optimum, the marginal loss in utility due to decreasing the private account equals the marginal utility from altruism. Comparatively, in the SocSig treatment $x$ is observed by Player C, meaning that Player A's actions are influenced by her self signaling and social image but not by reputation concerns. The corresponding FOC becomes

$$
u^{\prime}(100-x)=v^{\prime}(x)+S I_{A, j}^{\prime}(x)=v^{\prime}(x)+\lambda_{A, j} E_{A}\left(\omega_{j}(a)\right) \frac{d}{d x} \operatorname{Prob}_{j}\left(\sigma_{A}=a \mid x\right)
$$

It seems reasonable to assume that $\operatorname{Prob}_{j}\left(\sigma_{A}=a \mid x\right)$ is increasing in $x$. If we assume that both $\lambda_{A, j}$ and $E_{A}\left(\omega_{j}(a)\right)$ are positive, we can hypothesize that the optimal $x$ in SocSig is higher than in SelfSig, since $u$ is concave.

Hypothesis 1: The average amount transferred to the charity should be higher in SocSig than in SelfSig.

This stated, notice that, if either $\lambda_{A, j}$ or $E_{A}\left(\omega_{j}(a)\right)$ are negative, we could observe a lower $x$ in SocSig.

In the Reputation treatment, only player B can observe $x$. Here, besides $S I, y$ can also be influenced by $x$. We get the FOC

$$
\begin{aligned}
u^{\prime}(100-x) & =v^{\prime}(x)+w^{\prime}(E(y \mid x)) \frac{d}{d x} E(y \mid x)+S I_{A, j}^{\prime} \\
& =\lambda_{A, j} E_{A}\left(\omega_{j}(a)\right) \frac{d}{d x} \operatorname{Prob}_{j}\left(\sigma_{A}=a \mid x\right)
\end{aligned}
$$

Since $E(y \mid x)$ should depend positively on $x$, we get the following hypothesis:

Hypothesis 2: The average amount transferred to the charity should be higher in Reputation than in SocSig. ${ }^{11}$

\footnotetext{
${ }^{11}$ An alternative assumption would follow the crowding-out literature (Bénabou and Tirole, 2006, for experimental findings also see Frey and Oberholzer-Gee, 1997; Gneezy and Rustichini, 2000). This would suggest that individuals donate out of pure altruism (and potential social image concerns) in SocSig, whereas behavior in the Reputation condition is driven by monetary concerns as well. We instead follow the model
} 
Behavior in the Baseline measures pure altruism. Comparing the optimal $\mathrm{x}$ in Treatment 2 with that in the Baseline informs us about the role of social image in promoting pro-social (giving) behavior. In comparison to SelfSig, Reputation captures both social image and pure reputation concerns, and therefore resembles indirect reciprocity. Finally, the impact of pure reputation concerns is captured by the difference of $x$ in SocSig and Reputation. In our analysis, instead of the precise magnitude of $x$, its sign is of interest. While negative values of $x$ could certainly be regarded as a social norm violation, $x=0$ is the default, and any positive values of $x$ should boost both $S I$ and $y$. Therefore, we also formulate a hypothesis with respect to observed frequencies of certain types of behavior.

Hypothesis 1*: The frequency of positive (negative) values of $x$ should be higher (lower) in SocSig than in SelfSig.

Hypothesis 2*: The frequency of positive (negative) values of $x$ should be higher (lower) in Reputation than in SocSig.

\subsection{Results}

Our design allows us to look at the effects of reputation concerns, self-signaling, and social signaling both on the intensive and extensive margin. We first investigate the intensive margin, examining the magnitude of shifts in charitable giving, and then the extensive margin, in this case the frequency of pro-social (giving) and anti-social (taking) behavior. Unless otherwise specified, all reported p-values are the result of non-parametric tests.

\section{Magnitude of Behavior}

In this section, we attempt to answer: do the sums of money that Player A took away from or gave to charity differ across treatments? Figure 4 displays the net percentage change in the charity account due to Player A's actions. A positive (negative) number indicates a net benefit (net loss) for the charity. ${ }^{12}$

predictions as outlined above and our results support this decision empirically, as will be illustrated shortly.

${ }^{12}$ We also provide a breakdown of net increase/decrease in charity box in its giving and taking components and present the results in the Appendix Figure A.2 
Consistent with what was anticipated in our hypotheses section, the largest spike of pro-social behavior appears in the treatment in which Player A's behavior was directly observed by Player B (Reputation). Here, participants donated $40.9 \%$ of their initial endowment, larger than for the self-signaling (SelfSig) or social signaling (SocSig) treatment. Mann-Whitney-U (MWU) test statistics indicate a highly significant difference between Reputation and the two other treatments $(\mathrm{p}<0.01$ and $\mathrm{p}<0.001$, respectively).

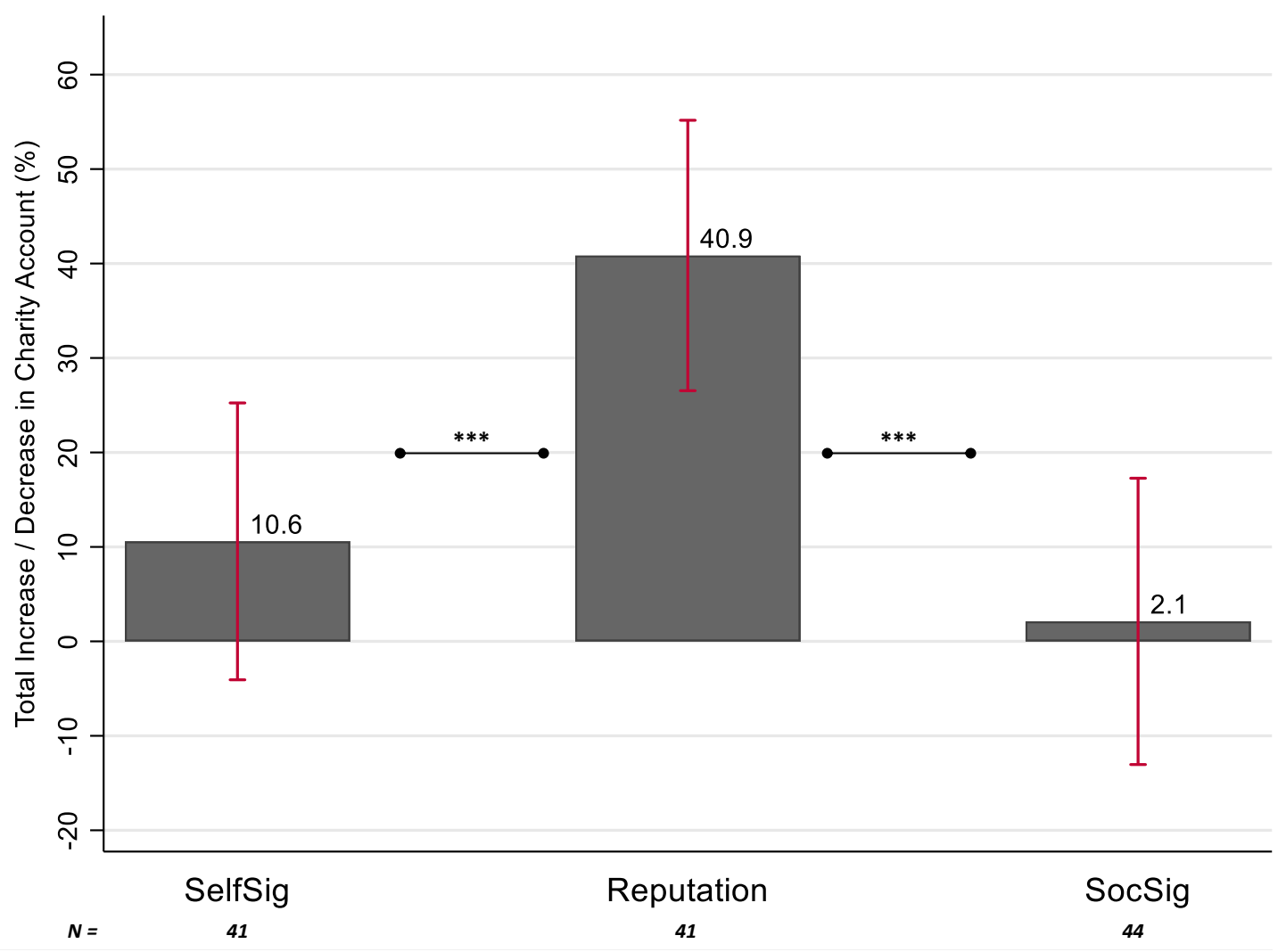

Figure 4: Magnitude of Behavior across treatments. Observations per treatment are displayed at the bottom of each column. Horizontal lines with stars represent statistical significance at ${ }^{* * *} \mathrm{p}<0.01,{ }^{* *} \mathrm{p}<0.05$, and $* \mathrm{p}<0.1$. Absence of horizontal implies lack of statistical significance at the conventional levels. Vertical lines represent $95 \%$ CIs.

Surprisingly, however, is that net contributions fall with the introduction of social signaling; $10.6 \%$ SelfSig versus $2.1 \%$ SocSig. While this difference is not statistically significant 
$(\mathrm{p}=0.61)$, the direction of the change is in stark contrast to the theoretical predictions. ${ }^{13}$

Tobit regressions reported in Table 2 add some detail to the differences we observe in contribution levels as discussed in Figure $4 .{ }^{14}$

\begin{tabular}{|c|c|c|c|}
\hline Tobit & Total Change & Taking Behavior Only & Giving Behavior Only \\
\hline \multicolumn{4}{|l|}{ DV: Magnitude of Behavior } \\
\hline \multicolumn{4}{|l|}{ Treatment (Base: SelfSig) } \\
\hline T1 (Reputation) & $\begin{array}{c}36.7121^{* * * *} \\
(11.7116)\end{array}$ & $\begin{array}{l}-7.6487 \\
(29.1729)\end{array}$ & $\begin{array}{l}16.5604 \\
(10.1505)\end{array}$ \\
\hline T2 (SocSig) & $\begin{array}{l}-8.5966 \\
(11.4833)\end{array}$ & $\begin{array}{l}-10.1245 \\
(15.4497)\end{array}$ & $\begin{array}{l}-7.6050 \\
(10.2936)\end{array}$ \\
\hline Male & $\begin{array}{l}-5.9332 \\
(10.3051)\end{array}$ & $\begin{array}{c}-30.4434^{*} \\
(17.0774)\end{array}$ & $\begin{array}{c}13.4626 \\
(8.9359)\end{array}$ \\
\hline Belief & $\begin{array}{c}0.1302^{*} \\
(0.0681)\end{array}$ & $\begin{array}{l}-0.0580 \\
(0.0948)\end{array}$ & $\begin{array}{c}0.1204^{* *} \\
(0.0583)\end{array}$ \\
\hline Risk & $\begin{array}{c}11.6083^{*} \\
(5.8973)\end{array}$ & $\begin{array}{l}7.0525 \\
(7.6509)\end{array}$ & $\begin{array}{l}0.7836 \\
(5.0126)\end{array}$ \\
\hline Self-Control & $\begin{array}{c}11.2135^{* *} \\
(4.9180)\end{array}$ & $\begin{array}{l}-0.5202 \\
(7.7866)\end{array}$ & $\begin{array}{l}3.8886 \\
(4.2690)\end{array}$ \\
\hline Charity Important & $\begin{array}{l}2.5261 \\
(2.8858)\end{array}$ & $\begin{array}{l}2.4012 \\
(3.3773)\end{array}$ & $\begin{array}{l}0.1741 \\
(2.7240)\end{array}$ \\
\hline \multicolumn{4}{|l|}{ Charity } \\
\hline UNICEF & $\begin{array}{l}-9.2678 \\
(12.0584)\end{array}$ & $\begin{array}{l}27.2867 \\
(18.8187)\end{array}$ & $\begin{array}{l}-1.3159 \\
(10.9712)\end{array}$ \\
\hline WWF & $\begin{array}{l}12.0783 \\
(12.0132)\end{array}$ & $\begin{array}{l}-19.0679 \\
(21.4336)\end{array}$ & $\begin{array}{l}7.9163 \\
(9.7211)\end{array}$ \\
\hline Constant & $\begin{array}{c}-23.9032 \\
(26.5569)\end{array}$ & $\begin{array}{l}-58.0120 * \\
(29.3506)\end{array}$ & $\begin{array}{c}24.6867 \\
(27.0542)\end{array}$ \\
\hline Post-estimation test T1 vs T2 & $p<0.01$ & $p=0.93$ & $p=0.011$ \\
\hline Observations & 126 & 25 & 76 \\
\hline
\end{tabular}

Table 2: Tobit regressions with standard errors in parentheses. ***,**, and * indicate significance at the $1 \%$, $5 \%$, and $10 \%$ level, respectively. Results are available upon request. Gender (1= male); Belief (amount A beliefs about B's reimbursement decision); Risk (higher number = more risk-seeking, standardized measure); Self-Control (higher number = more self-control, standardized measure); Charity Important (higher number $=$ higher preference for charities in general); Charity (higher number $=$ higher preference for the respective charity, Doctors Without Borders is the reference category).

Across multiple specifications, we find significantly different behavior in the Reputation treatment, which is in line with our non-parametric results. For total change and giving

\footnotetext{
${ }^{13}$ We also investigate whether player A's behavior paid off with respect to the reimbursement obtained through player B. This is not central to our analysis and we present the results in Appendix Figure A.3.

${ }^{14}$ The distribution of behavior indicates a clustering at the extreme bounds, for which our Tobit regression model can control. We present histograms in the Appendix.
} 
behavior, our results also suggest a significantly positive link between Player A's behavior and her beliefs about the extent of reimbursement Player B will provide through the transfer from the cash box, leading to significantly more giving when higher reimbursement is anticipated. ${ }^{15}$ Note that in line with our previous surprise funding, the post-estimation test between Reputation and SocSig treatment suggests a significantly lower amount of money given to charity, both in terms of total giving as well as giving behavior only. We do not observe a significant difference for taking behavior only and conclude that the exposure to a passive third party particularly affects giving.

\section{Frequency of Behavior}

Next, we examine individual heterogeneity with respect to the distribution of behavior categories (taking, no change, and giving) and break it out across treatments in Figure 5. Focusing first on the shift in the Reputation distribution we observe much as we would expect under Hypotheses $1^{*}$ and $2^{*}$ and the magnitude shift analyzed above: Anti-social behavior is significantly less frequent in the Reputation treatment compared to SelfSig (4.88\% vs. 21.95\%, Equality of Proportions Test (EPT), p=0.02) and SocSig (4.88\% vs. $31.82 \%$, EPT, $\mathrm{p}<0.01$ ). Pro-social behavior is significantly more frequent in the Reputation treatment compared to SelfSig $(78.05 \%$ vs. $48.72 \%$, EPT, p $<0.01)$ and SocSig $(78.05 \%$ vs. $54.55 \%$, EPT, $\mathrm{p}=0.02$ ).

The analogous investigation of 'no change' reveals a weakly significant decrease in SocSig relative to SelfSig ( $13.6 \%$ vs. $29.3 \%$, EPT, $\mathrm{p}=0.078$ ). Further, we observe two sizable but insignificant changes in behavior: as anticipated by Hypothesis $1^{*}$, the directional change of giving behavior indicates an increase relative to SelfSig ( $54.5 \%$ vs. $48.8 \%$, EPT, $\mathrm{p}=0.595)$. But contrary to Hypothesis $1^{*}$, the directional change of taking behavior yields an increase as well ( $31.8 \%$ vs. $22.0 \%$, EPT, p=0.306). Nevertheless, the offsetting increases, relative to SelfSig, in both giving and taking behavior help to explain why the the total contribution level fails to rise in SocSig as anticipated by Hypothesis $1^{*}$. All shifts between SocSig and Reputation treatments shown in Figure 5 are consistent with Hypothesis $2^{*}$ : giving behavior rises and taking behavior falls significantly. ${ }^{16}$

\footnotetext{
${ }^{15}$ As further examined in the Appendix Table A1, the role of beliefs differs across treatments as one would expect and in fact explains the difference between the SelfSig and Reputation conditions in its entirety.

${ }^{16}$ A further analysis relying on Fisher's exact chi-squared statistics reveals that behavior in our Reputation treatment differs substantially and significantly from behavior in the SelfSig treatment $(\mathrm{p}=0.02)$ and SocSig treatment $(\mathrm{p}<0.01)$. These differences can be attributed to an (under-) over-proportional observation of taking and giving behavior in the reputation treatment. Our chi-squared test statistic yields a p-value of
} 


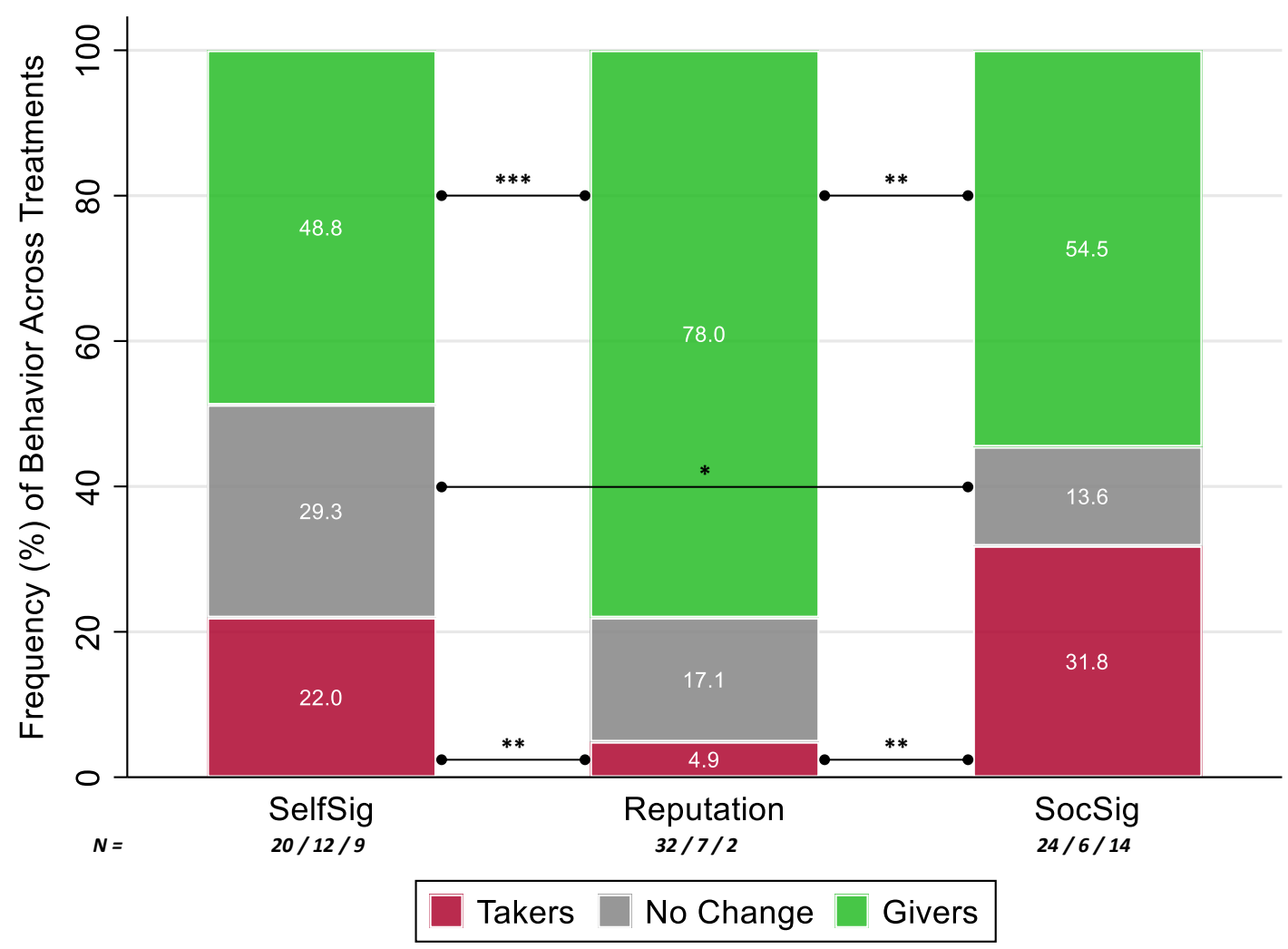

Figure 5: Frequency of behavior across treatments. Observations per treatment and type of behavior are displayed at the bottom of each column. Horizontal lines with stars represent statistical significance at $* * * \mathrm{p}<0.01,{ }^{* *} \mathrm{p}<0.05$, and ${ }^{*} \mathrm{p}<0.1$. Absence of horizontal implies lack of statistical significance at the conventional levels.

Logit regressions reported in Table 3 use SelfSig as the reference category, and like our previous regression analysis, control for a number of relevant covariates (gender, beliefs, measures of risk and self-control, and importance of charities). The results corroborate the previous non-parametric findings, indicating that reputation concerns, as presented in our Reputation treatment, reduce (increase) the frequency of taking (giving) behavior relative to both self-signaling (SelfSig) and social signaling (SocSig) concerns.

The coefficients of the covariates indicate that males engage more frequently in antisocial behavior, which is in line with findings on corruption and cheating behavior in

0.2 when comparing the distribution of behavior in the SelfSig versus SocSig treatments. 
existing literature (for a discussion, see Croson and Gneezy, 2009; Dimant and Tosato, 2018; Abeler et al., 2018). Conversely, we do not observe a statistically significant gender heterogeneity with respect to pro-social behavior. Our results also indicate that Player A's beliefs, the extent to which she thinks she will be reimbursed by Player B's transfer from the cash box, only weakly predict giving behavior. ${ }^{17}$ Notably, while the direction of the coefficients for SocSig suggest that both giving and taking behavior are more frequent compared to SelfSig, they do not reach significance. We report the results in Table 3.

\begin{tabular}{|c|c|c|c|c|c|c|c|c|}
\hline \multirow[b]{2}{*}{ DV: Frequency of Behavior } & \multicolumn{4}{|c|}{ Taking Behavior } & \multicolumn{4}{|c|}{ Giving Behavior } \\
\hline & $\begin{array}{c}\text { (1a) } \\
\text { Odds Ratios }\end{array}$ & $\begin{array}{c}\text { (1b) } \\
\text { Log-Odds }\end{array}$ & $\begin{array}{c}\text { (2a) } \\
\text { Odds Ratios }\end{array}$ & $\begin{array}{c}\text { (2b) } \\
\text { Log-Odds }\end{array}$ & \begin{tabular}{|c|} 
(1a) \\
Odds Ratios
\end{tabular} & $\begin{array}{c}\text { (1b) } \\
\text { Log-Odds }\end{array}$ & $\begin{array}{c}\text { (2a) } \\
\text { Odds Ratios }\end{array}$ & $\begin{array}{c}\text { (2b) } \\
\text { Log-Odds }\end{array}$ \\
\hline \multicolumn{9}{|l|}{ Treatment (Base: Anonymous) } \\
\hline T1 (Reputation) & $\begin{array}{c}0.1823^{* *} \\
(0.1496)\end{array}$ & $\begin{array}{c}-1.7019 * * \\
(0.8206)\end{array}$ & $\begin{array}{l}0.1403^{* *} \\
(0.1315)\end{array}$ & $\begin{array}{c}-1.9637^{* *} \\
(0.9367)\end{array}$ & $\begin{array}{c}3.7333^{* * *} \\
(1.8362)\end{array}$ & $\begin{array}{c}1.3173 * * * \\
(0.4918)\end{array}$ & $\begin{array}{l}4.1647^{* * *} \\
(2.2259)\end{array}$ & $\begin{array}{c}1.4266^{* * *} \\
(0.5345)\end{array}$ \\
\hline T2 (SocSig) & $\begin{array}{l}1.6593 \\
(0.8281)\end{array}$ & $\begin{array}{l}0.5064 \\
(0.4991)\end{array}$ & $\begin{array}{l}1.9133 \\
(1.0599)\end{array}$ & $\begin{array}{l}0.6488 \\
(0.5540)\end{array}$ & $\begin{array}{l}1.2600 \\
(0.5504)\end{array}$ & $\begin{array}{l}0.2311 \\
(0.4368)\end{array}$ & $\begin{array}{l}1.4302 \\
(0.6629)\end{array}$ & $\begin{array}{l}0.3578 \\
(0.4635)\end{array}$ \\
\hline Gender & & & $\begin{array}{l}3.3503^{* *} \\
(1.9703)\end{array}$ & $\begin{array}{c}1.2090 * * \\
(0.5881)\end{array}$ & & & $\begin{array}{l}1.1165 \\
(0.5079)\end{array}$ & $\begin{array}{l}0.1102 \\
(0.4549)\end{array}$ \\
\hline Self-Control & & & $\begin{array}{l}0.5561 * * \\
(0.1573)\end{array}$ & $\begin{array}{c}-0.5867^{* *} \\
(0.2829)\end{array}$ & & & $\begin{array}{l}1.4150 * \\
(0.2951)\end{array}$ & $\begin{array}{c}0.3471^{*} \\
(0.2086)\end{array}$ \\
\hline Charity Important & & & $\begin{array}{l}0.9501 \\
(0.1466)\end{array}$ & $\begin{array}{c}-0.0512 \\
(0.1543)\end{array}$ & & & $\begin{array}{l}1.1969 \\
(0.1454)\end{array}$ & $\begin{array}{l}0.1798 \\
(0.1215)\end{array}$ \\
\hline \multicolumn{9}{|l|}{ Charity } \\
\hline UNICEF & & & $\begin{array}{l}1.4981 \\
(0.8601)\end{array}$ & $\begin{array}{l}0.4042 \\
(0.5741)\end{array}$ & & & $\begin{array}{l}0.4445^{*} \\
(0.2131)\end{array}$ & $\begin{array}{c}-0.8107^{*} \\
(0.4794)\end{array}$ \\
\hline
\end{tabular}

Table 3: Logistic Regression. Coefficients denote Odds Ratios (OR). Standard errors in parenthesis. ***, **, and $*$ indicate significance at the 1\%,5\%, and $10 \%$ level, respectively. Gender $(1=$ male); Belief (amount A beliefs about B's reimbursement decision); Risk (higher number = more risk-seeking, standardized measure); Self-Control (higher number = more self-control, standardized measure); Charity Important (higher number $=$ higher preference for charities in general); Charity (higher number = higher preference for the respective charity, Doctors Without Borders are the reference category).

\footnotetext{
${ }^{17}$ Paralleling our previous analysis, we examine the role of beliefs in detail in the Appendix Table A2.
} 
In sum, in experiment 1, the existence of reputation concerns proved an effective means to increase (decrease) pro-social (anti-social) behavior with respect to the frequency at which such behavior occurs. This is in line both with the previously discussed literature and our hypotheses section. At the same time, contrary to initial expectation, the presence of social signaling failed to increase contributions, and descriptively, although not statistically, led to more extreme behavior, along both pro-social and anti-social dimensions, compared to a situation in which merely self-signaling concerns are present.

\section{Experiment 2: Online (mTurk)}

According to the literature (see above, particularly in the theory section) introducing observation by a third party should trigger greater norm observance and overall improve the outcome of the charity relative to the Baseline condition. Instead, Experiment 1 found no statistical effect and lead to a somewhat worse outcome for the charity in the presence of a passive third-party observer, in particular with respect to the amount given to (rather than taken from) charity. Having been surprised by this result, we designed a second experiment to investigate whether the strength of the social observation effect is related to the strength of attention drawn to the norm as some theory suggests. We conducted this test on Amazon's mTurk. In addition to testing the new hypothesis, we test the robustness of our laboratory findings in SelfSig and SocSign to a different population and with a substantial boost in statistical power made possible by a larger sample. ${ }^{18}$

The new experiment tests the hypothesis that nudging people to think more about the norms others might follow affects the efficacy of the observation intervention by triggering greater norm compliance (Cialdini et al., 1990, 1991). Hence, in addition to replicating our SelfSig and SocSig laboratory results, we run two new treatments in which we vary the norm focus capitalizing on the approach of Krupka and Weber (2009).

\subsection{Design}

Following our particular interest in examining the role of observation in affecting Player A's dictator game decision with a taking option, we implemented a simplified version of

\footnotetext{
${ }^{18}$ To ensure high quality data on mTurk, we utilize a combination of CAPTCHAs and screening questions to avoid pool contamination. We applied the following restrictions to the participant pool: participants had to be in the U.S., approval rate was greater than $99 \%$ on mTurk, and they had not taken this study before. Snowberg and Yariv (2018) discuss the robustness of behavior on mTurk versus laboratory settings.
} 
our previous laboratory design. We removed Player B altogether and focused solely on Player A's behavior towards a charity with (SocSig) and without (SelfSig) observation by Player C. By removing Player B, we retain a clean design that focus more specifically on the behavioral impact of social signaling in these two treatments. ${ }^{19}$

In concordance with Focus Theory (Cialdini et al., 1990, 1991), we expect that manipulating the strength of the norm focus, by drawing attention to the norm, can render the social signal nudge more effectively (for a discussion of when and how norm focus is effective, see Kallgren et al. 2000). Our treatment variation follows the focus intervention designed by Krupka and Weber (2009): we elicited incentivized beliefs right before participants were able to make their decision with respect to giving to or taking from the charity. The belief elicitation aimed at putting more focus on the norm by asking participants what they thought other participants in the same situation had done previously. Whether or not the stated belief was correct was disclosed to the participants only at the very end of the experiment; that is, after they have made their own giving or taking decision towards the charity. As Krupka and Weber (2009) have shown, such a belief elicitation can increase giving in a dictator game and is thus the right approach for our setup (a variant of a dictator game). We refer to these treatments as SelfSig BE and SocSig BE, respectively. Figure A.4 and Figure A.5 in the Appendix illustrate the design features in detail.

\subsection{Participants and Procedures}

The one-shot between subjects design of these two treatments mirrors the design implemented in our lab experiment. Participants and the respective charities started with an endowment of $\$ 1$ each and the payment mechanism remained the same as in Experiment 1 with the exception that Player B was not present anymore. Correct beliefs were incentivized with an additional $\$ 0.5$. We collected data for a total of 819 participants in the role of Player $\mathrm{A}^{20}$, of which $49.4 \%$ were female, and the average age was 33.7 years. From start to finish, the duration of a treatment was 10 minutes. This yielded an average

\footnotetext{
${ }^{19}$ One implication from this is that, in expected value, A's income is reduced because no reimbursement through B's Cash Box will be possible anymore. This design choice has the advantage that we limit the impact that the observability through $\mathrm{C}$ can have on A's behavior to the necessary minimum, allowing us to focus on a clean identification of the observability effect.

${ }^{20}$ Due to the nature of mTurk experiments, data for Players $\mathrm{C}$ was collected after finishing collecting data for Players A, which is appropriate given the passive nature of Player C. As before, all our analyses focus on the behavior of Player A.
} 
hourly income of $\$ 7.72$ for Player $\mathrm{A}$, an amount well above what is typically paid on mTurk (Arechar et al., 2017). We donated a total amount of $\$ 1,435.82$ to our three charities. ${ }^{21}$

\begin{tabular}{lcccc}
\hline \hline & \multicolumn{4}{c}{ mTurk Treatments } \\
\cline { 2 - 5 } & SelfSig & SelfSig BE & SocSig & SocSig BE \\
\hline Participants & 226 & 188 & 221 & 184 \\
Female & $46 \%$ & $49 \%$ & $47 \%$ & $58 \%$ \\
Age (average) & 35.3 & 31.2 & 35.9 & 31.7 \\
\hline
\end{tabular}

Table 4: Descriptive Statistics for Player A.

\subsection{Results}

In line with our previous discussion, we split the analysis into two parts: Magnitude of contribution and frequency of pro- and anti-social behavior for all four treatments (SelfSig and SocSig with and without belief elicitation). We present the beliefs for the two belief elicitation (BE) treatments in the Appendix in Figure A.6.

\section{Magnitude of Behavior}

First, we examine the results presented in Figure 6. Looking first at the baseline treatments, SelfSig and SocSig, we observe that mTurk subjects are less charitable overall than are the subjects in our laboratory experiments. That said, while the magnitudes of contribution differ, the key result is that SocSig leads to a significant reduction in generous behavior overall (-28.3\% vs. $-18.4 \%$, MWU, $\mathrm{p}=0.0401)$. This result corroborates our suggestive findings of Experiment 1 in the laboratory. ${ }^{22}$

Result 1: The social signaling nudge alone (SocSig) leads to more extreme anti-social behavior compared to SelfSig.

Within each condition, we observe that the norm focus intervention substantially increases (decreases) the monetary amounts given to (taken from) charity, both in the SelfSig

\footnotetext{
${ }^{21}$ We find that mTurk participants are significantly older than our lab sample $(\mathrm{p}<0.01)$ and a more equal male to female ratio $(p=0.02)$. We do not find any significant differences in risk-taking behavior $(p=0.14)$. For a comprehensive discussion of commonalities and differences between lab and mTurk populations, see Arechar et al. (2017, 2018); Snowberg and Yariv (2018).

${ }^{22}$ We present the distribution of behavior across treatments in the Appendix in Figure A.8.
} 


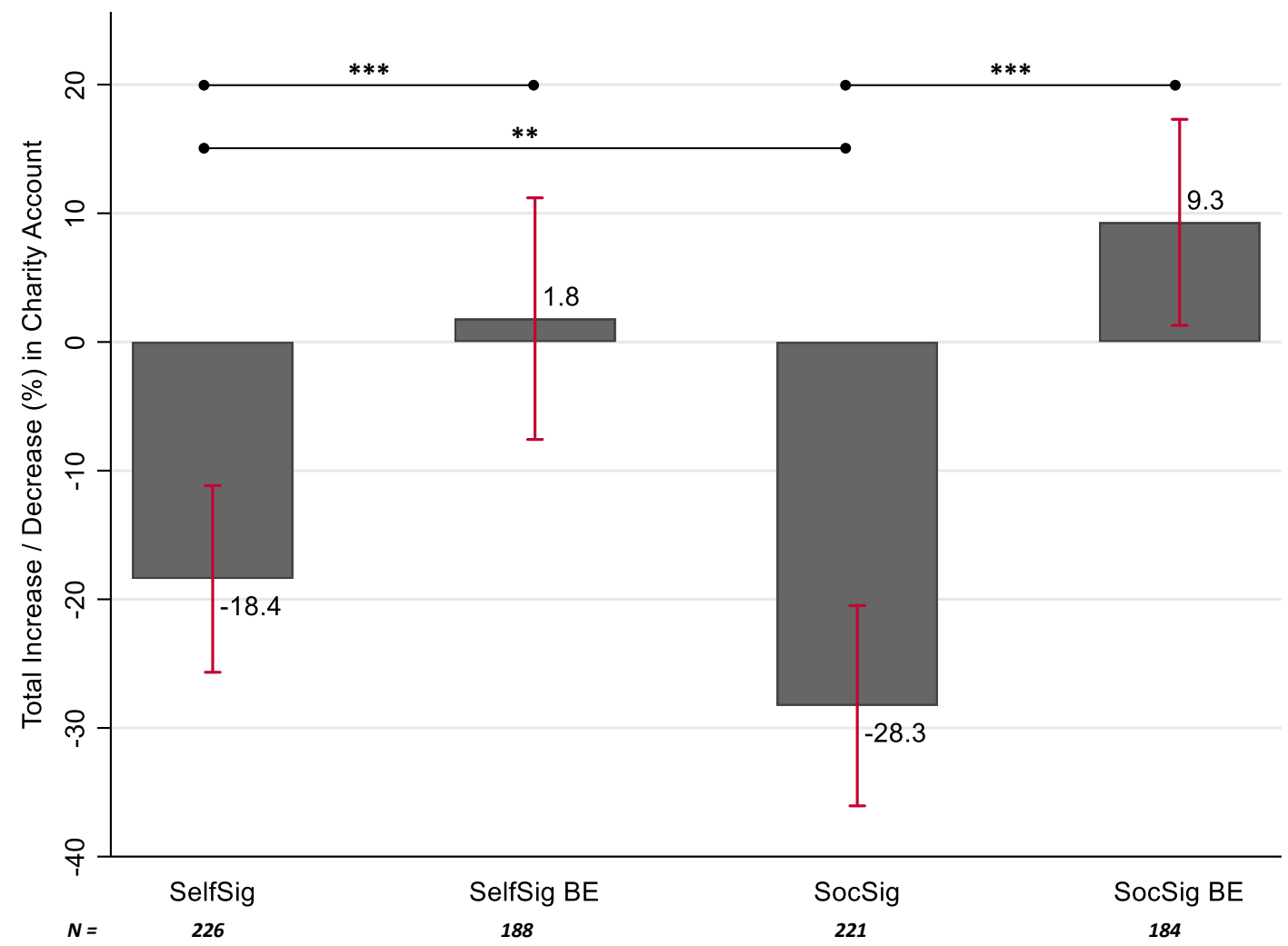

Figure 6: Change in charity box (in monetary amounts) across treatments. Observations per treatment and type of behavior are displayed at the bottom of each column. Horizontal lines with stars represent statistical significance at $* * * \mathrm{p}<0.01$, ** $\mathrm{p}<0.05$, and $* \mathrm{p}<0.1$. Absence of horizontal implies lack of statistical significance at the conventional levels.

(1.8\% vs. $-18.4 \%$, MWU, $\mathrm{p}<0.001)$ as well as the SocSig $(9.3 \%$ vs. $-28.3 \%$, MWU, $\mathrm{p}<0.001)$ treatments. These findings suggest that a norm focus through the use of belief elicitation can revert the anti-social tendencies of individuals. We do not observe the norm focus to exert a differential impact on SocSig (9.6\% vs. 1.8\%, MWU, $\mathrm{p}=0.392)$.

Result 2: The norm focus intervention works in the expected direction in the form of increasing (decreasing) the magnitude of giving (taking) behavior.

Next, we analyze the magnitude of giving and taking behavior separately, which we graphically illustrate in the Appendix in Figure A.7. The data suggests that Result 1 - 
more extreme behavior in SocSig compared to SelfSig - is explained through both more extreme giving behavior, $(66.4 \%$, vs. $51.7 \%$, MWU, $\mathrm{p}=0.018)$ and taking behavior $(-90.6 \%$ vs. $-81.4 \%$, MWU, $\mathrm{p}=0.012$ ) alike. For giving behavior alone, we find that the norm focus only improves behavior for SelfSig ( $65.4 \%$ vs. $51.7 \%$, MWU, p=0.018) but does not at all affect giving in SocSig. For taking behavior alone, our results suggest that norm focus significantly reduces the extent of taking for SocSig (-72.6\% vs. $-90.6 \%, \mathrm{MWU}, \mathrm{p}<0.001)$, while behavior in SelfSig remains entirely invariant.

In a final step, we examine behavior through the lens of Tobit regressions (to account for the censoring nature of the data) and present the results in Table 5. While this analysis corroborates the main non-parametric findings discussed above, we also observe a number of additional noteworthy insights. For one, we observe that norm focus yields an over-proportional increase in the charity box for SocSig. When subdividing this total effect into its sub-components, we see that this result is driven by an extreme and highly significant upward reaction of taking behavior and an equally significant but comparably smaller downward reaction for giving behavior. The positive (negative) coefficient for taking (giving) behavior indicates that amplifying social signaling with a norm focus leads to a substantial reduction of this behavior relative to behavior in the SelfSig conditions.

\begin{tabular}{lccc}
\hline \multicolumn{1}{c}{ Tobit } & Total Change & Taking Behavior Only & Giving Behavior Only \\
\hline \multirow{2}{*}{ DV: Magnitude of Behavior } & & & \\
\hline \multirow{2}{*}{ SocSig } & $-12.1982^{*}$ & $-28.0252^{* *}$ & $18.2704^{*}$ \\
\multirow{2}{*}{ Norm Focus (BE) } & $(6.9459)$ & $(11.3363)$ & $(9.6754)$ \\
& $28.7867^{* * *}$ & -4.6302 & $18.1138^{* *}$ \\
& $(7.4330)$ & $(12.3808)$ & $(7.8773)$ \\
\multirow{2}{*}{ SocSig $\times$ Norm Focus (BE) } & $21.6767^{* *}$ & $54.6300^{* * *}$ & $-24.0088^{* *}$ \\
Male & $(10.2374)$ & $(18.1546)$ & $(11.8613)$ \\
& $17.1365^{* * *}$ & $17.7192^{*}$ & 7.5523 \\
Risk & $(5.2483)$ & $(9.2520)$ & $(5.6006)$ \\
& $0.4280^{*}$ & 0.3427 & 0.2830 \\
Age & $(0.2483)$ & $(0.4550)$ & $(0.2863)$ \\
& -1.3720 & 0.0110 & 1.1333 \\
& $(1.1103)$ & $(1.8046)$ & $(1.2934)$ \\
\hline \multirow{2}{*}{ Constant } & $-63.5654^{* * *}$ & $-152.3571^{* * *}$ & $29.3511^{*}$ \\
\hline \multirow{2}{*}{ Observations } & $(14.5629)$ & $(24.5814)$ & $(16.8338)$ \\
\hline
\end{tabular}

Table 5: Tobit Regression. Standard errors in parenthesis. ***,**, and * indicate significance at the $1 \%$, $5 \%$, and $10 \%$ level, respectively. Gender $(1=$ male); Risk (higher number $=$ more risk-seeking, standardized measure); Age (higher number = older). 
These results are surprising and hence deserve more exploration. The findings suggest that even the mere thought of what other people do creates a behavioral reaction similar to the norm-based intervention as described by Schultz et al. (2007). There, the authors describe a boomerang effect of norm interventions that capitalize on a descriptive normative message involving telling individuals the exact extent of an undesired behavior (excessive energy consumption) of their peers. Exposing the actual behavior produced either desirable energy savings or an undesirable boomerang effect, depending on whether the individuals in this condition were initially consuming at a low or high rate. Strikingly, our results suggest that such an intervention can backfire even without exposure to actual peer behavior, which can at least partially be attributed to the beliefs the participants hold about the behavior of others (see Figure A.6 in the appendix). The mere focus on what behavior could be is seemingly sufficient to backfire and is in line with what has recently been documented by Bicchieri and Dimant (2018) for lying behavior.

\section{Frequency of Behavior}

The first noteworthy finding is that the initial surprising result from Experiment 1 reproduces, and now yields, a statistically significant difference between SelfSig and SocSig in the form of reduced giving behavior frequency in SocSig (13.6\% vs. 20.8\%, EPT, $\mathrm{p}=0.042) .{ }^{23}$ We do not observe any significant differences for taking or no change behavior.

Result 1: In line with results in Experiment 1, the social signaling nudge alone (SocSig) is insufficient in facilitating giving behavior or reducing taking behavior. In fact, social signaling even backfires and substantially reduces giving behavior.

Next, we examine the impact of the norm focus intervention and observe a high rate of effectiveness overall. The results indicate that norm focus has the largest impact on the frequency of giving behavior, both in the SelfSig (39.4\% vs. 20.8\%, EPT, p <0.001) and SocSig $(36.8 \%$ vs. $13.6 \%$, EPT, $\mathrm{p}<0.001)$ conditions. This stark increase in compliance comes at the expense of both taking and no change behavior. In particular, we observe that an increased norm focus also yields significantly less frequent taking behavior, again

\footnotetext{
${ }^{23}$ This finding can be harmonized not only with higher statistical power, but also with respect to the Focus Theory: the absence of Player B leads to a reduced focus, in particular in the SocSig condition, allowing for the difference with SelfSig to be more strongly pronounced than in Experiment 1.
} 
both for the SelfSig ( $28.2 \%$ vs. $35.8 \%$, EPT, marginally significant at $\mathrm{p}=0.098)$ as well as the SocSig $(20.7 \%$ vs. $41.2 \%, \mathrm{EPT}, \mathrm{p}<0.001)$ conditions. Lastly, we observe that the focus intervention also leads to a significant reduction of no change behavior $(32.4 \%$ vs. $43.4 \%$, EPT, $\mathrm{p}=0.023 ; 40.8 \%$ vs. $45.2 \%, \mathrm{p}=0.096)$. We present the results in Figure 7.

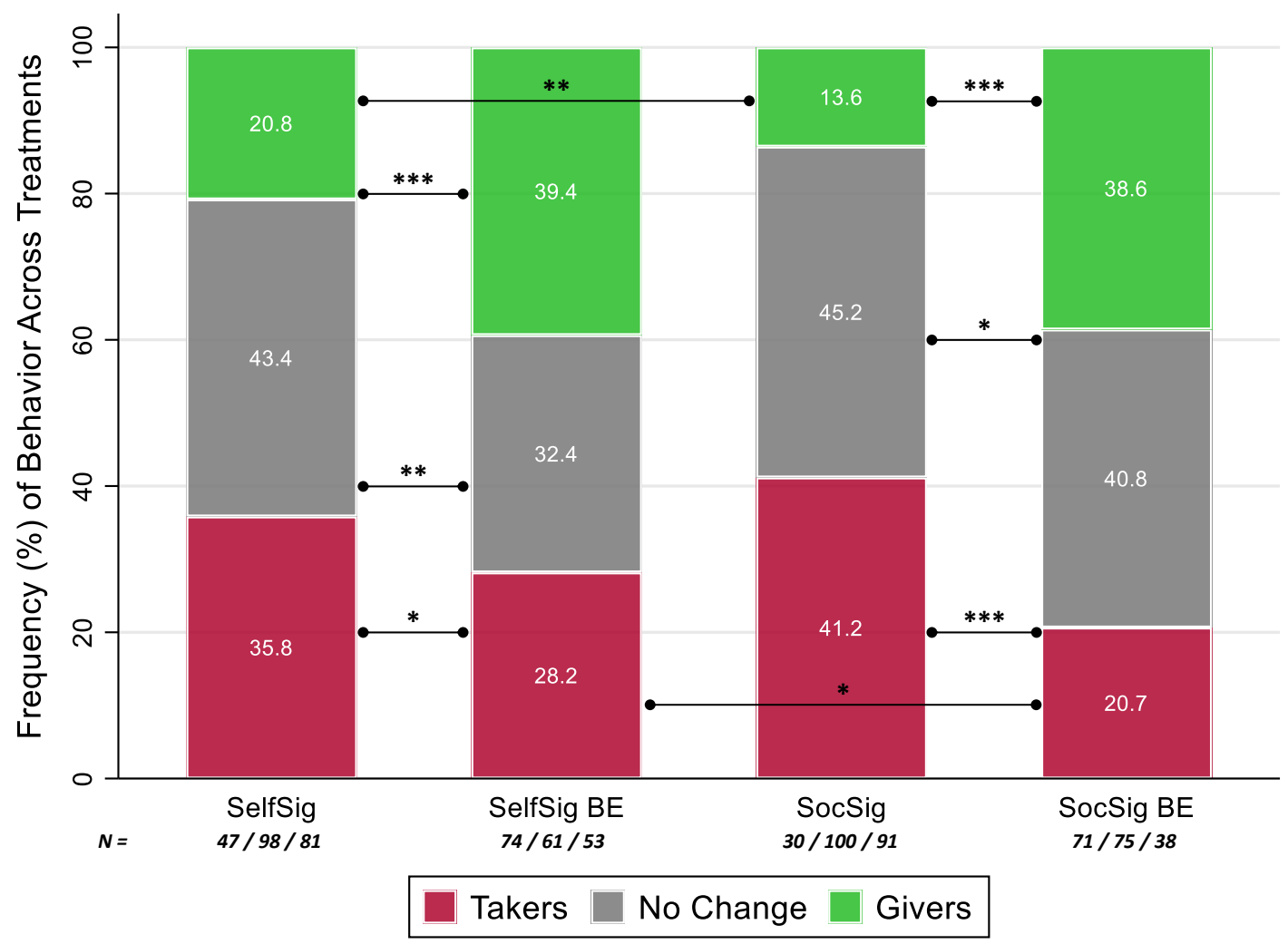

Figure 7: Change in charity box (in frequencies) across treatments. Observations per treatment are displayed at the bottom of each column in the top-down order. Horizontal lines with stars represent statistical significance at $* * * \mathrm{p}<0.01,{ }^{*} \mathrm{p}<0.05$, and $* \mathrm{p}<0.1$. Absence of horizontal implies lack of statistical significance at the conventional levels.

Result 2: The norm focus intervention works in the expected direction in the form of increasing (decreasing) the frequency of giving (taking) behavior.

We perform a Logit regression (Table 6) to tease out the extent to which both social signaling as well as the norm focus affect the likelihood of individuals to engage in either 
taking or giving behavior after controlling for gender, age, and risk attitudes to capture specific characteristics of mTurkers. In line with our non-parametric results presented above, social signaling only reduces (marginally) the frequency of giving behavior, while the effect of norm focus in SelfSig has a substantial effect in reducing taking and increasing giving behavior. We also find indications of a marginally significant and negative interaction effect for taking behavior, suggesting that a social signaling nudge can be rendered more effective in reducing the frequency of anti-social behavior when paired with a norm focus. The absence of a significant interaction for giving behavior suggests that pairing a social signaling nudge with a norm focus intervention can eliminate the backfiring effect.

\begin{tabular}{|c|c|c|c|c|}
\hline \multirow{2}{*}{$\frac{\text { Logit }}{\text { DV: Frequency of Behavior }}$} & \multicolumn{2}{|c|}{ Taking Behavior } & \multicolumn{2}{|c|}{ Giving Behavior } \\
\hline & $\begin{array}{c}\text { (1a) } \\
\text { Odds Ratios }\end{array}$ & $\begin{array}{c}\text { (1b) } \\
\text { Log-Odds }\end{array}$ & $\begin{array}{c}\text { (2a) } \\
\text { Odds Ratios }\end{array}$ & $\begin{array}{c}\text { (2b) } \\
\text { Log-Odds }\end{array}$ \\
\hline SocSig & $\begin{array}{l}1.1975 \\
(0.2309)\end{array}$ & $\begin{array}{l}0.1803 \\
(0.1928)\end{array}$ & $\begin{array}{c}0.6260 * \\
(0.1598)\end{array}$ & $\begin{array}{c}-0.4683^{*} \\
(0.2552)\end{array}$ \\
\hline Norm Focus (BE) & $\begin{array}{c}0.5830 * * \\
(0.1300)\end{array}$ & $\begin{array}{c}-0.5395^{* *} \\
(0.2230)\end{array}$ & $\begin{array}{c}2.4988 * * * \\
(0.5787)\end{array}$ & $\begin{array}{c}0.9158^{* * * *} \\
(0.2316)\end{array}$ \\
\hline SocSig $\times$ Norm Focus $(B E)$ & $\begin{array}{c}0.5685^{*} \\
(0.1797)\end{array}$ & $\begin{array}{c}-0.5647^{*} \\
(0.3161)\end{array}$ & $\begin{array}{l}1.5315 \\
(0.5099)\end{array}$ & $\begin{array}{l}0.4262 \\
(0.3329)\end{array}$ \\
\hline Male & $\begin{array}{l}0.6237^{* * * *} \\
(0.0978)\end{array}$ & $\begin{array}{c}-0.4721 * * * \\
(0.1568)\end{array}$ & $\begin{array}{l}1.0777 \\
(0.1819)\end{array}$ & $\begin{array}{l}0.0748 \\
(0.1688)\end{array}$ \\
\hline Risk & $\begin{array}{c}0.9870 * \\
(0.0075)\end{array}$ & $\begin{array}{c}-0.0130 * \\
(0.0076)\end{array}$ & $\begin{array}{l}0.9985 \\
(0.0085)\end{array}$ & $\begin{array}{c}-0.0015 \\
(0.0085)\end{array}$ \\
\hline Age & $\begin{array}{c}1.0641^{*} \\
(0.0355)\end{array}$ & $\begin{array}{c}0.0622 * \\
(0.0334)\end{array}$ & $\begin{array}{l}1.0191 \\
(0.0355)\end{array}$ & $\begin{array}{l}0.0189 \\
(0.0348)\end{array}$ \\
\hline Observations & 828 & 828 & 828 & 828 \\
\hline
\end{tabular}

Table 6: Logistic Regression, odds ratios displayed. Coefficients denote Odds Ratios (OR). Standard errors in parenthesis. $* * *, * *$, and $*$ indicate significance at the $1 \%, 5 \%$, and $10 \%$ level, respectively. Gender $(1=$ male); Risk (higher number = more risk-seeking, standardized measure); Age (higher number $=$ older).

In sum, these results allow us to harmonize our previous surprising results suggesting that observation can lead to more extreme behavior and can backfire even in combination with a norm focusing intervention. These are particularly important insights from a policy perspective and we will return to its discussion in our conclusion. 


\section{Conclusion}

Individuals commonly engage in behaviors that constitute a trade-off between selfserving and other-regarding goals. Typically, the trade-offs a person makes are subject to observation by peers and hence embody concerns related to social signaling, as well as self-signaling, that self and social image as well as reputation effects influencing future reciprocity. The extent to which there is observation is generally thought to provide a pro-social nudge. Empirically, however, disentangling these channels is difficult because they rarely appear in isolation. To make matters more complicated, the trade-offs involved are often embedded in strategic environments in which individual and social welfare can be influenced by observors. What is more, most past studies of observability have focused on its impact on decisions in the pro-social domain alone (Bradley et al., 2018).

We study the impact of an observability nudge in both the pro- and anti-social domain and systematically disect the different channels at play. We capitalize on both a laboratory and online setting to ensure the robustness of our results and explore the mechanisms at play in more detail (Snowberg and Yariv, 2018). We complement our experimental analysis with a theory section, in which we derive two sets of testable hypotheses using a model that capitalizes on the following three distinct drivers of behavior: self-interest, altruism/warmglow, and social image. Broadly speaking, the model predicts that social image observation will be more successful at curbing anti-social behavior and promoting pro-social behavior, and that reciprocal reputation mechanisms will be most impactful.

The latter prediction of the model, that reciprocity will be most successful at reducing anti-social behavior and increasing pro-social behavior is confirmed by our data. This finding is in line with the standard literature on reputation concerns and indirect reciprocity. Surprisingly, however, the combined evidence from the first experiment (laboratory), and the second experiment (mTurk) lead us to the conclusion that social image observation, that is being observed by an otherwise uninvolved third party without the ability to enforce behavior, can boost both pro- and anti-social behavior, especially the extent to which either behavior occurs. Not only does the social image nudge fail to yield the expected benefit, it even seems to backfire.

A number of obvious hypotheses involve factors held fixed in our experiment. These include economic self-interest, the size of the stakes in the experiment, and experimenter observation effects. While these factors might play a role in some of the observed behavior, they cannot easily explain changes observed across treatments. An alternative explanation 
proposed in recent literature is that one's equity concerns change depending on whether or not one is observed, thus making this reference group more salient (Exley and Kessler, 2018). If true, this could partially address why behavior becomes more anti-social when observed by a passive third-party: one does not want to fall behind this person; a feeling which, arguably, would not persist without the observation of this party. We can exclude this channel by design: instructions were always the same in all treatments and for all participants, explicitly emphasizing the presence of others and their payoffs. Only then were participants randomized into roles and treatments, hence controlling for the salience of the peer presence. This methodological approach also allows us rule out that differential demand effects could explain the observed treatment differences (Zizzo, 2010).

Instead, the Focus Theory (Cialdini et al., 1990, 1991) provides a viable explanation. Applied to our set-up the theory implies that that observation without enforcement can enhance the salience of selfishness, which can be alleviated by increasing the focus on the underlying norm of pro-social behavior. We designed Experiment 2 to examine this hypothesis. In line with the assumptions, observability without monetary reinforcement reduced the amount transferred to the charity significantly. In line with our laboratory results, the amounts given, and taken, were larger when participants were observed when monetary concerns were absent. In other words, observation alone produces more extreme behavior in our setup, both on the pro-social and on the anti-social side. But also in line with the Focus Theory hypothesis, when we ask subjects to think about what others would do prior to making their own decisions, we observe that the social observation nudge reverses the backfiring effect and works similarly to observation with monetary concerns. In a way, making a behavioral norm salient resembles the presence of monetary consequences.

Altogether, we can conclude that in situations where both pro- and anti-social behavior is possible, nudges increasing the observability of one's actions have little or even detrimental effects when monetary consequences are absent. Relying on one's social image consideration alone can likely be insufficient. Policymakers need to be aware of this potential backfiring effect. A crucial aspect we detected in this case is the salience of social norms (Bicchieri and Dimant, 2018). Increasing the salience of norms reverts the strongly detrimental impact of the pure observability nudge. Our take-away is that in situations in which behavior cannot be enforced or sanctioned, nudges increasing observability of actions should be combined with a salient norm to avoid potential backfiring effects, which compared to the costly introduction of formal institutions - yields an effective and efficient intervention both in social and economic terms. 


\section{References}

Abeler, J., Nosenzo, D., and Raymond, C. (2018). Preferences for truth-telling. Econometrica.

Akerlof, G. A. (1980). A theory of social custom, of which unemployment may be one consequence. The quarterly journal of economics, 94(4):749-775.

Alexander, R. (1987). The biology of moral systems. Aldine De Gruyter.

Alpízar, F. and Martinsson, P. (2013). Does it matter if you are observed by others? evidence from donations in the field. The Scandinavian Journal of Economics, 115(1):74-83.

Andreoni, J. (1990). Impure altruism and donations to public goods: A theory of warm-glow giving. The economic journal, 100(401):464-477.

Andreoni, J. and Bernheim, B. D. (2009). Social image and the 50-50 norm: A theoretical and experimental analysis of audience effects. Econometrica, 77(5):1607-1636.

Arechar, A. A., Gächter, S., and Molleman, L. (2018). Conducting interactive experiments online. Experimental Economics, 21(1):99-131.

Arechar, A. A., Kraft-Todd, G. T., and Rand, D. G. (2017). Turking overtime: How participant characteristics and behavior vary over time and day on Amazon Mechanical Turk. Journal of the Economic Science Association, 3(1):1-11.

Ayres, I., Raseman, S., and Shih, A. (2013). Evidence from two large field experiments that peer comparison feedback can reduce residential energy usage. The Journal of Law, Economics, and Organization, 29(5):992-1022.

Azrieli, Y., Chambers, C. P., and Healy, P. J. (2018). Incentives in experiments: A theoretical analysis. Journal of Political Economy, 126(4):1472-1503.

Balliet, D., Wu, J., and De Dreu, C. K. (2014). Ingroup favoritism in cooperation: A meta-analysis. Psychological Bulletin, 140(6):1556.

Bardsley, N. (2008). Dictator game giving: altruism or artefact? Experimental Economics, 11(2):122-133.

Becker, G. S. (1968). Crime and punishment: An economic approach. In The economic dimensions of crime, pages 13-68. Springer.

Bénabou, R. and Tirole, J. (2006). Incentives and prosocial behavior. American economic review, 96(5):1652-1678.

Bénabou, R. and Tirole, J. (2011). Identity, morals, and taboos: Beliefs as assets. The Quarterly Journal of Economics, 126(2):805-855.

Benartzi, S., Beshears, J., Milkman, K. L., Sunstein, C. R., Thaler, R. H., Shankar, M., TuckerRay, W., Congdon, W. J., and Galing, S. (2017). Should governments invest more in nudging? Psychological science, 28(8):1041-1055.

Beshears, J., Choi, J. J., Laibson, D., Madrian, B. C., and Milkman, K. L. (2015). The effect of providing peer information on retirement savings decisions. The Journal of finance, 70(3):11611201. 
Bicchieri, C. and Dimant, E. (2018). It's not a lie if you believe it: Lying and belief distortion under norm-uncertainty. PPE Working Paper 0012, University of Pennsylvania.

Bicchieri, C., Dimant, E., Gaechter, S., and Nosenzo, D. (2018a). Social similarity and the erosion of social norms. Technical report, Mimeo.

Bicchieri, C., Dimant, E., and Xiao, E. (2018b). Deviant or wrong? the effects of norm information on the efficacy of punishment. PPE Working Paper 0016, University of Pennsylvania.

Bolton, G., Greiner, B., and Ockenfels, A. (2013). Engineering trust: reciprocity in the production of reputation information. Management science, 59(2):265-285.

Bolton, G. E., Katok, E., and Ockenfels, A. (2004). How effective are electronic reputation mechanisms? an experimental investigation. Management science, 50(11):1587-1602.

Bradley, A., Lawrence, C., and Ferguson, E. (2018). Does observability affect prosociality? Proc. R. Soc. B, 285(1875):20180116.

Brandon, A., Ferraro, P. J., List, J. A., Metcalfe, R. D., Price, M. K., and Rundhammer, F. (2017). Do the effects of social nudges persist? theory and evidence from 38 natural field experiments. Technical report, National Bureau of Economic Research.

Buchan, N. R., Croson, R. T., and Dawes, R. M. (2002). Swift neighbors and persistent strangers: A cross-cultural investigation of trust and reciprocity in social exchange. American Journal of Sociology, 108(1):168-206.

Bursztyn, L. and Jensen, R. (2017). Social image and economic behavior in the field: Identifying, understanding, and shaping social pressure. Annual Review of Economics, 9:131-153.

Cappelen, A. W., Halvorsen, T., Sørensen, E. Ø., and Tungodden, B. (2017). Face-saving or fair-minded: What motivates moral behavior? Journal of the European Economic Association, 15(3):540-557.

Charness, G., Gneezy, U., and Halladay, B. (2016). Experimental methods: Pay one or pay all. Journal of Economic Behavior \& Organization, 131:141-150.

Cialdini, R. B., Kallgren, C. A., and Reno, R. R. (1991). A focus theory of normative conduct: A theoretical refinement and reevaluation of the role of norms in human behavior. In Advances in experimental social psychology, volume 24, pages 201-234. Elsevier.

Cialdini, R. B., Reno, R. R., and Kallgren, C. A. (1990). A focus theory of normative conduct: Recycling the concept of norms to reduce littering in public places. Journal of personality and social psychology, 58(6):1015.

Coffman, L. C. (2011). Intermediation reduces punishment (and reward). American Economic Journal: Microeconomics, 3(4):77-106.

Cooper, D. J. and Kagel, J. H. (2016). Other-regarding preferences. The handbook of experimental economics, 2:217.

Croson, R. and Gneezy, U. (2009). Gender differences in preferences. Journal of Economic literature, $47(2): 448-74$.

Damgaard, M. T. and Gravert, C. (2018). The hidden costs of nudging: Experimental evidence from reminders in fundraising. Journal of Public Economics, 157:15-26. 
Dana, J., Cain, D. M., and Dawes, R. M. (2006). What you don't know won't hurt me: Costly (but quiet) exit in dictator games. Organizational Behavior and human decision Processes, 100(2):193-201.

Dana, J., Weber, R. A., and Kuang, J. X. (2007). Exploiting moral wiggle room: experiments demonstrating an illusory preference for fairness. Economic Theory, 33(1):67-80.

Dimant, E. (2018). Contagion of pro-and anti-social behavior among peers and the role of social proximity. Working paper, The Centre for Decision Research and Experimental Economics, School of Economics, University of Nottingham.

Dimant, E. and Tosato, G. (2018). Causes and effects of corruption: what has past decade's empirical research taught us? a survey. Journal of Economic Surveys, 32(2):335-356.

Dufwenberg, M. and Muren, A. (2006). Generosity, anonymity, gender. Journal of Economic Behavior \& Organization, 61(1):42-49.

Ekström, M. (2012). Do watching eyes affect charitable giving? evidence from a field experiment. Experimental Economics, 15(3):530-546.

Ernest-Jones, M., Nettle, D., and Bateson, M. (2011). Effects of eye images on everyday cooperative behavior: a field experiment. Evolution and Human Behavior, 32(3):172-178.

Exley, C. L. and Kessler, J. B. (2018). Equity concerns are narrowly framed. Harvard business school working paper 18-040, Harvard University.

Falk, A. and Fischbacher, U. (2002). "crime" in the lab-detecting social interaction. European Economic Review, 46(4-5):859-869.

Falk, A. and Tirole, J. (2016). Narratives, imperatives and moral reasoning. Mimeo.

Festré, A. and Garrouste, P. (2015). Theory and evidence in psychology and economics about motivation crowding out: A possible convergence? Journal of Economic Surveys, 29(2):339-356.

Fischbacher, U. (2007). z-tree: Zurich toolbox for ready-made economic experiments. Experimental economics, 10(2):171-178.

Forsythe, R., Horowitz, J. L., Savin, N. E., and Sefton, M. (1994). Fairness in simple bargaining experiments. Games and Economic behavior, 6(3):347-369.

Frey, B. S. and Oberholzer-Gee, F. (1997). The cost of price incentives: An empirical analysis of motivation crowding-out. The American economic review, 87(4):746-755.

Gino, F., Ayal, S., and Ariely, D. (2009). Contagion and differentiation in unethical behavior: The effect of one bad apple on the barrel. Psychological science, 20(3):393-398.

Gneezy, U. and Rustichini, A. (2000). A fine is a price. The Journal of Legal Studies, 29(1):1-17.

Grimalda, G., Pondorfer, A., and Tracer, D. P. (2016). Social image concerns promote cooperation more than altruistic punishment. Nature communications, 7:12288.

Haley, K. J. and Fessler, D. M. (2005). Nobody's watching?: Subtle cues affect generosity in an anonymous economic game. Evolution and Human behavior, 26(3):245-256. 
Hallsworth, M., Chadborn, T., Sallis, A., Sanders, M., Berry, D., Greaves, F., Clements, L., and Davies, S. C. (2016). Provision of social norm feedback to high prescribers of antibiotics in general practice: a pragmatic national randomised controlled trial. The Lancet, 387(10029):1743-1752.

Hamman, J. R., Loewenstein, G., and Weber, R. A. (2010). Self-interest through delegation: An additional rationale for the principal-agent relationship. American Economic Review, 100(4):182646.

Kajackaite, A. and Sliwka, D. (2017). Social responsibility and incentives in the lab: Why do agents exert more effort when principals donate? Journal of Economic Behavior $\mathcal{E}$ Organization, 142:482-493.

Kallgren, C. A., Reno, R. R., and Cialdini, R. B. (2000). A focus theory of normative conduct: When norms do and do not affect behavior. Personality and social psychology bulletin, 26(8):1002-1012.

Krupka, E. and Weber, R. A. (2009). The focusing and informational effects of norms on pro-social behavior. Journal of Economic psychology, 30(3):307-320.

Lacetera, N. and Macis, M. (2010). Do all material incentives for pro-social activities backfire? the response to cash and non-cash incentives for blood donations. Journal of Economic Psychology, $31(4): 738-748$.

Lambarraa, F. and Riener, G. (2015). On the norms of charitable giving in islam: Two field experiments in morocco. Journal of Economic Behavior \&3 Organization, 118:69-84.

Lazear, E. P., Malmendier, U., and Weber, R. A. (2012). Sorting in experiments with application to social preferences. American Economic Journal: Applied Economics, 4(1):136-63.

List, J. A. (2007). On the interpretation of giving in dictator games. Journal of Political economy, 115(3):482-493.

Madrian, B. C. (2014). Applying insights from behavioral economics to policy design. Annu. Rev. Econ., 6(1):663-688.

Matland, R. E. and Murray, G. R. (2016). I only have eyes for you: Does implicit social pressure increase voter turnout? Political Psychology, 37(4):533-550.

Nowak, M. A. and Sigmund, K. (1998a). The dynamics of indirect reciprocity. Journal of theoretical Biology, 194(4):561-574.

Nowak, M. A. and Sigmund, K. (1998b). Evolution of indirect reciprocity by image scoring. Nature, 393(6685):573.

Reijula, S., Kuorikoski, J., Ehrig, T., Katsikopoulos, K., Sunder, S., et al. (2018). Nudge, boost, or design? limitations of behaviorally informed policy under social interaction. Journal of Behavioral Economics for Policy, 2(1):99-105.

Richter, I., Thøgersen, J., and Klöckner, C. (2018). A social norms intervention going wrong: Boomerang effects from descriptive norms information. Sustainability, 10(8):2848.

Rilke, R. M., Danilov, A., Irlenbusch, B., Weisel, O., and Shalvi, S. (2018). The honest leader effect-how hierarchies affect honesty in groups. In Academy of Management Proceedings, volume 2018, page 10365. Academy of Management Briarcliff Manor, NY 10510. 
Rogers, T., Goldstein, N. J., and Fox, C. R. (2018). social mobilization. Annual review of psychology, 69:357-381.

Schultz, P. W., Nolan, J. M., Cialdini, R. B., Goldstein, N. J., and Griskevicius, V. (2007). The constructive, destructive, and reconstructive power of social norms. Psychological science, 18(5):429434 .

Snowberg, E. and Yariv, L. (2018). Testing the waters: Behavior across participant pools. Working Paper 24781, National Bureau of Economic Research.

Szaszi, B., Palinkas, A., Palfi, B., Szollosi, A., and Aczel, B. (2018). A systematic scoping review of the choice architecture movement: Toward understanding when and why nudges work. Journal of Behavioral Decision Making, 31(3):355-366.

Thaler, R. and Sunstein, C. (2008). Nudge: Improving Decisions about Health, Wealth, and Happiness. Yale University Press.

Xiao, E. and Houser, D. (2011). Punish in public. Journal of Public Economics, 95(7-8):1006-1017.

Zizzo, D. J. (2010). Experimenter demand effects in economic experiments. Experimental Economics, 13(1):75-98. 


\section{Appendix}

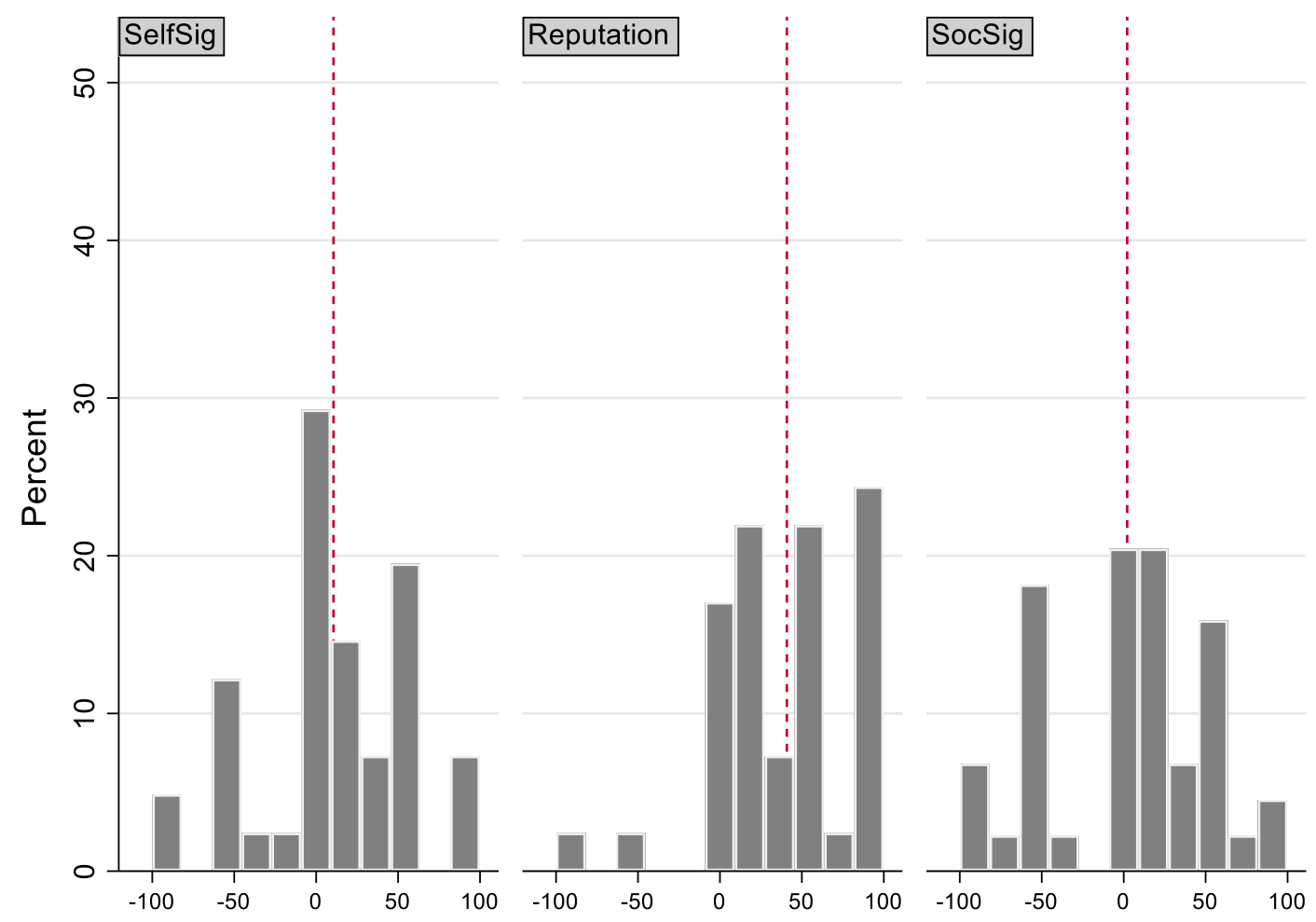

Figure A.1: Distribution of change in charity box (in monetary amounts) across treatments. 


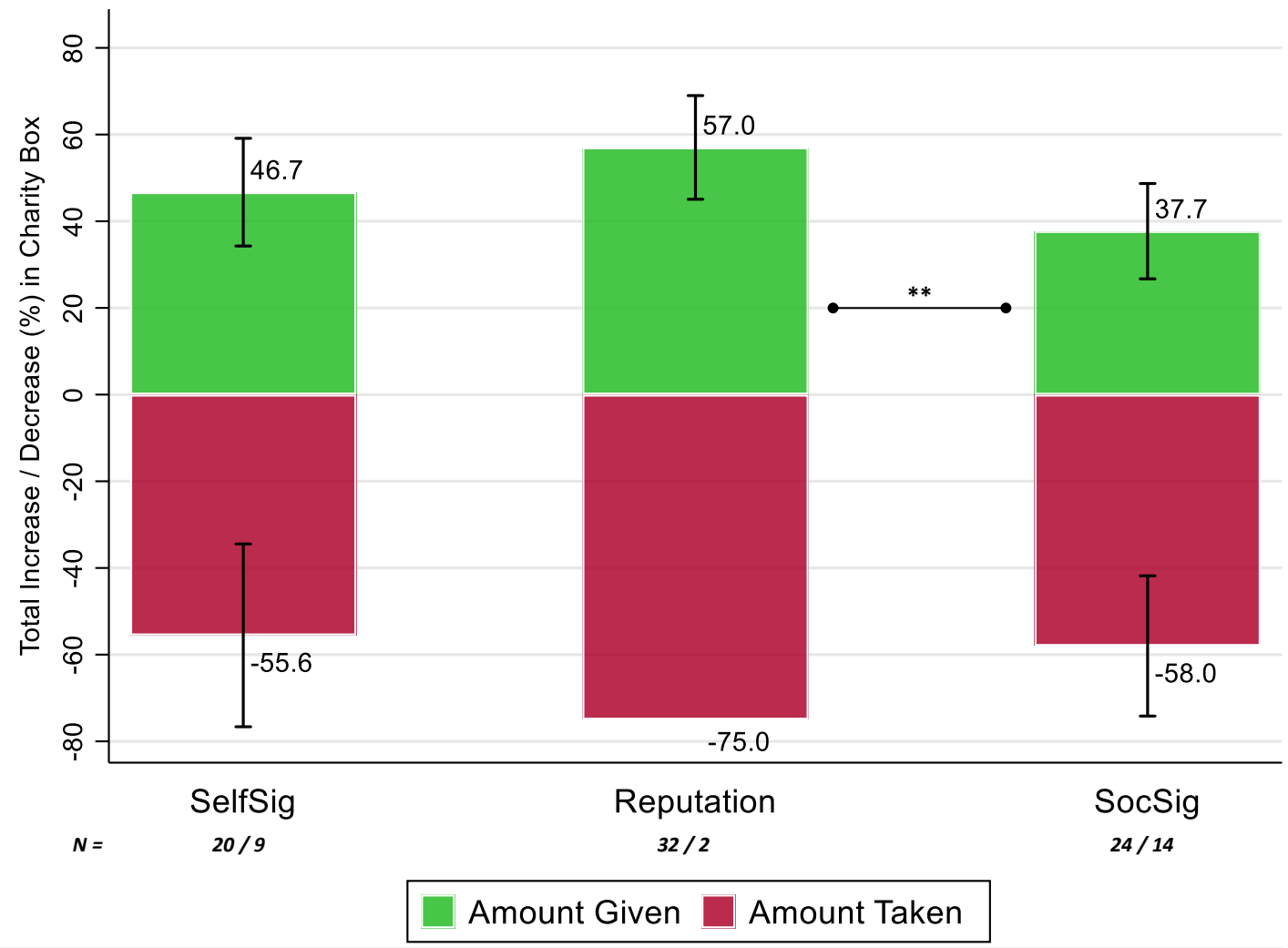

Figure A.2: Magnitude of Behavior across treatments. Observations per treatment are displayed at the bottom of each column in the top-down order. Horizontal lines with stars represent statistical significance at ${ }^{* * *} \mathrm{p}<0.01, * * \mathrm{p}<0.05$, and $* \mathrm{p}<0.1$. Absence of horizontal implies lack of statistical significance at the conventional levels. Vertical lines represent 95\% CIs. Note: 95\% CI for taking behavior in Reputation suppressed because of $n=2$.

\section{Does Player A's Behavior Pay Off?}

We are interested in understanding whether Player A's behavior towards the charity has paid off and, if so, to what extent. In order to test this, we compare Player A's dictatorial decision (the monetary amount she took out of her own endowment and gave to charity) to the reimbursement she received from Player B's cash box across treatments (the final amount that she received after a multiplier of two was applied).

Our results indicate that the average reimbursement granted by Player B is identical in both the self-signaling (Baseline) and social signaling (T2) specification. This is to be expected based on the theoretical reasoning provided in section 2. In both treatments, Player B did not actually get to observe Player A's behavior but had to rely on her own 
expectations. In monetary terms, our findings suggest that Player A's behavior paid off, but more so in the social signaling (T2) treatment than in the self-signaling (Baseline) treatment due to a more pronounced amount of anti-social behavior. The differences are significant at the $5 \%$ level $(10.6 \%$ vs. $41.0 \%$, MWU p $=0.04)$ and $1 \%$ level $(2.1 \%$ vs. $40.9 \%$, MWU $\mathrm{p}<0.01)$, respectively. Moreover, we observe the inverse pattern for the reputation (T1) treatment. Not only do participants in this treatment behave more prosocially on average, but the observation of this behavior also leads to a substantially lower reimbursement amount by Player B. Although this difference is not statistically significant ( $40.9 \%$ vs. $27.8 \%$, MWU p=0.29), the results indicate that, on average, Player A's behavior did not pay off in this treatment. One explanation is that this result is driven by Player B's disenchantment with Player A's magnitude of pro-sociality. We report the results in Figure A.3.

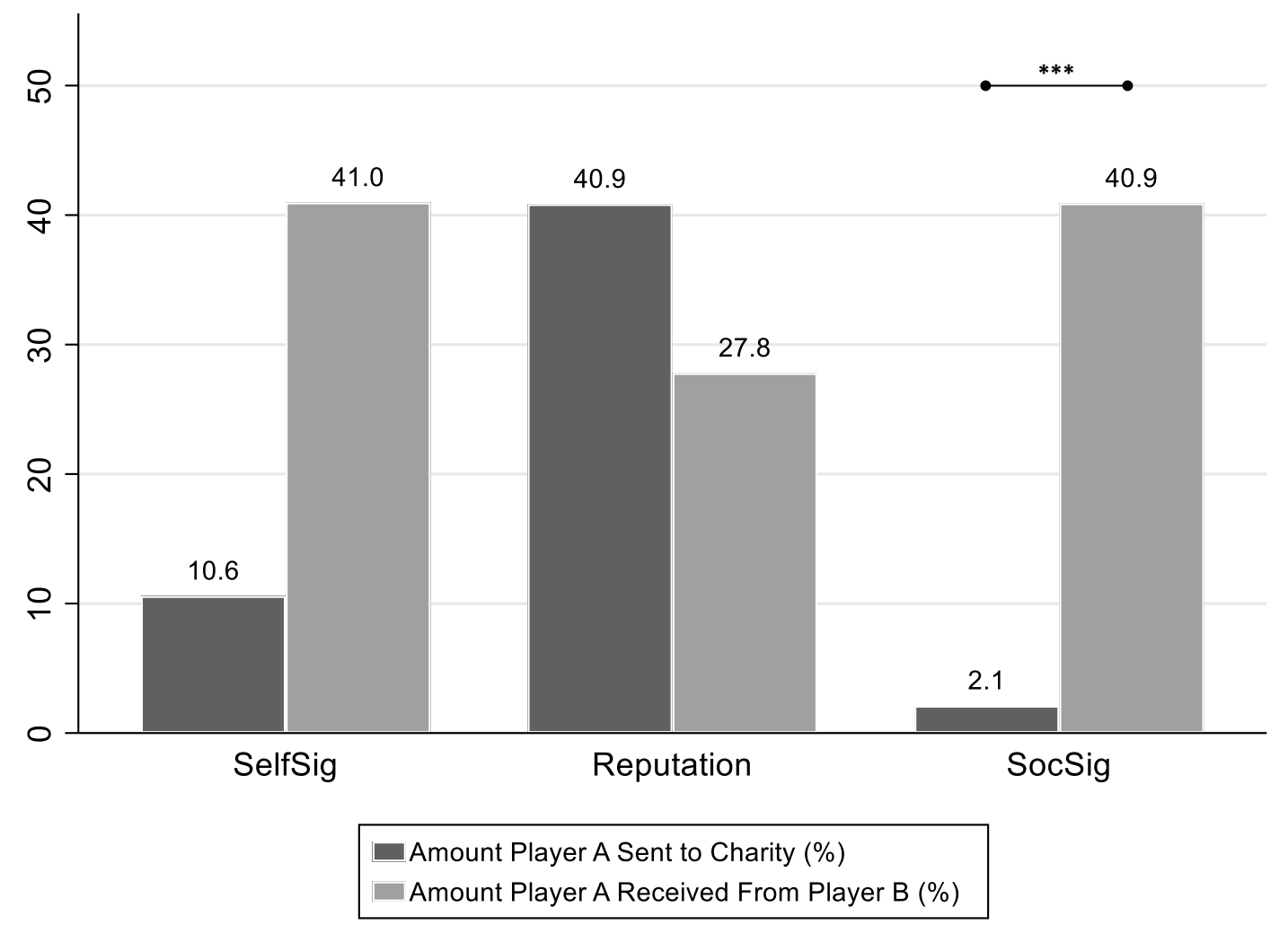

Figure A.3: Magnitude of Behavior Across Treatments. 


\begin{tabular}{|c|c|c|c|c|c|c|}
\hline \multirow{2}{*}{$\frac{\text { Tobit }}{\text { DV: Magnitude of Behavior }}$} & \multicolumn{2}{|c|}{ Total Change } & \multicolumn{2}{|c|}{ Taking Behavior Only } & \multicolumn{2}{|c|}{ Giving Behavior Only } \\
\hline & (1) & $(2)$ & (3) & (4) & (5) & (6) \\
\hline \multicolumn{7}{|l|}{ Treatment (Base: SelfSig) } \\
\hline T1 (Reputation) & $\begin{array}{c}36.712 * * * \\
(11.712)\end{array}$ & $\begin{array}{l}-8.341 \\
(20.544)\end{array}$ & $\begin{array}{l}-7.649 \\
(29.173)\end{array}$ & $\begin{array}{l}-167.545 \\
(8136.681)\end{array}$ & $\begin{array}{l}16.560 \\
(10.151)\end{array}$ & $\begin{array}{r}-25.526 \\
(18.723)\end{array}$ \\
\hline T2 (SocSig) & $\begin{array}{l}-8.597 \\
(11.483)\end{array}$ & $\begin{array}{c}-12.338 \\
(19.631)\end{array}$ & $\begin{array}{r}-10.125 \\
(15.445)\end{array}$ & $\begin{array}{c}-15.872 \\
(26.015)\end{array}$ & $\begin{array}{l}-7.605 \\
(10.294)\end{array}$ & $\begin{array}{r}-21.276 \\
(18.717)\end{array}$ \\
\hline Belief & $\begin{array}{c}0.130^{*} \\
(0.068)\end{array}$ & $\begin{array}{l}0.006 \\
(0.107)\end{array}$ & $\begin{array}{r}-0.058 \\
(0.095)\end{array}$ & $\begin{array}{l}-0.122 \\
(0.155)\end{array}$ & $\begin{array}{c}0.120 * * \\
(0.058)\end{array}$ & $\begin{array}{l}-0.036 \\
(0.097)\end{array}$ \\
\hline \multicolumn{7}{|l|}{ Treatment $\times$ Belief } \\
\hline T1 (Reputation) × Belief & & $\begin{array}{c}0.436^{* * *} \\
(0.166)\end{array}$ & & $\begin{array}{c}1.873 \\
(81.367)\end{array}$ & & $\begin{array}{c}0.367^{* *} \\
(0.140)\end{array}$ \\
\hline T2 (SocSig) × Belief & & $\begin{array}{l}0.017 \\
(0.160)\end{array}$ & & $\begin{array}{l}0.056 \\
(0.212)\end{array}$ & & $\begin{array}{l}0.098 \\
(0.141)\end{array}$ \\
\hline Male & $\begin{array}{l}-5.933 \\
(10.305)\end{array}$ & $\begin{array}{c}-9.864 \\
(10.355)\end{array}$ & $\begin{array}{c}-30.443^{*} \\
(17.077)\end{array}$ & $\begin{array}{c}-31.297^{*} \\
(16.4195)\end{array}$ & $\begin{array}{c}13.463 \\
(8.936)\end{array}$ & $\begin{array}{l}8.527 \\
(9.160)\end{array}$ \\
\hline Risk & $\begin{array}{c}11.608^{*} \\
(5.897)\end{array}$ & $\begin{array}{c}11.017^{*} \\
(5.763)\end{array}$ & $\begin{array}{l}7.053 \\
(7.651)\end{array}$ & $\begin{array}{l}6.665 \\
(7.472)\end{array}$ & $\begin{array}{l}0.784 \\
(5.013)\end{array}$ & $\begin{array}{l}0.004 \\
(4.823)\end{array}$ \\
\hline Self-Control & $\begin{array}{c}11.214^{* *} \\
(4.918)\end{array}$ & $\begin{array}{c}12.203^{* *} \\
(4.808)\end{array}$ & $\begin{array}{r}-0.520 \\
(7.787)\end{array}$ & $\begin{array}{l}-0.857 \\
(7.731)\end{array}$ & $\begin{array}{l}3.889 \\
(4.269)\end{array}$ & $\begin{array}{l}6.052 \\
(4.185)\end{array}$ \\
\hline Charity Important & $\begin{array}{l}2.526 \\
(2.886)\end{array}$ & $\begin{array}{l}2.653 \\
(2.808)\end{array}$ & $\begin{array}{l}2.401 \\
(3.377)\end{array}$ & $\begin{array}{l}2.545 \\
(3.290)\end{array}$ & $\begin{array}{l}0.174 \\
(2.724)\end{array}$ & $\begin{array}{l}0.003 \\
(2.602)\end{array}$ \\
\hline \multicolumn{7}{|l|}{ Charity } \\
\hline UNICEF & $\begin{array}{l}-9.268 \\
(12.058)\end{array}$ & $\begin{array}{c}-10.642 \\
(11.790)\end{array}$ & $\begin{array}{l}27.287 \\
(18.819)\end{array}$ & $\begin{array}{l}31.525 \\
(20.815)\end{array}$ & $\begin{array}{l}-1.316 \\
(10.971)\end{array}$ & $\begin{array}{l}-0.104 \\
(10.523)\end{array}$ \\
\hline WWF & $\begin{array}{l}12.078 \\
(12.013)\end{array}$ & $\begin{array}{l}11.674 \\
(11.685)\end{array}$ & $\begin{array}{c}-19.068 \\
(21.434)\end{array}$ & $\begin{array}{l}-5.275 \\
(23.220)\end{array}$ & $\begin{array}{l}7.916 \\
(9.721)\end{array}$ & $\begin{array}{l}6.946 \\
(9.309)\end{array}$ \\
\hline Constant & $\begin{array}{c}-23.903 \\
(26.557)\end{array}$ & $\begin{array}{l}-9.437 \\
(26.707)\end{array}$ & $\begin{array}{c}-58.012^{*} \\
(29.351)\end{array}$ & $\begin{array}{c}-54.706^{*} \\
(28.699)\end{array}$ & $\begin{array}{l}24.687 \\
(27.054)\end{array}$ & $\begin{array}{c}47.282^{*} \\
(27.686)\end{array}$ \\
\hline Post-estimation test T1 vs T2 & $p<0.01$ & $p=0.85$ & $p=0.93$ & $p=0.99$ & $p=0.011$ & $p=0.81$ \\
\hline Observations & 126 & 126 & 25 & 25 & 76 & 76 \\
\hline
\end{tabular}

Table A1: Tobit regressions with standard errors in parentheses. ***, **, and * indicate significance at the $1 \%, 5 \%$, and $10 \%$ level, respectively. Results are available upon request. Gender $(1=$ male); Belief (amount A beliefs about B's reimbursement decision); Risk (higher number = more risk-seeking, standardized measure); Self-Control (higher number = more self-control, standardized measure); Charity Important (higher number $=$ higher preference for charities in general); Charity (higher number $=$ higher preference for the respective charity, Doctors Without Borders is the reference category). 


\begin{tabular}{|c|c|c|c|c|c|c|c|c|}
\hline \multirow{2}{*}{$\begin{array}{c}\text { Logit } \\
\text { DV: Frequency of Behavior }\end{array}$} & \multicolumn{4}{|c|}{ Taking Behavior } & \multicolumn{4}{|c|}{ Giving Behavior } \\
\hline & $\begin{array}{c}\text { (1a) } \\
\text { Odds Ratios }\end{array}$ & $\begin{array}{c}\text { (1b) } \\
\text { Log-Odds }\end{array}$ & $\begin{array}{c}\text { (2a) } \\
\text { Odds Ratios }\end{array}$ & $\begin{array}{c}\text { (2b) } \\
\text { Log-Odds }\end{array}$ & $\begin{array}{c}\text { (1a) } \\
\text { Odds Ratios }\end{array}$ & $\begin{array}{c}\text { (1b) } \\
\text { Log-Odds }\end{array}$ & $\begin{array}{c}\text { (2a) } \\
\text { Odds Ratios }\end{array}$ & $\begin{array}{c}\text { (2b) } \\
\text { Log-Odds }\end{array}$ \\
\hline \multicolumn{9}{|l|}{ Treatment (Base: Anonymous) } \\
\hline T1 (Reputation) & $\begin{array}{c}0.182 * * \\
(0.150)\end{array}$ & $\begin{array}{c}-1.702 * * \\
(0.821)\end{array}$ & $\begin{array}{l}1.742 \\
(2.145)\end{array}$ & $\begin{array}{l}0.555 \\
(1.232)\end{array}$ & $\begin{array}{c}3.733^{* * *} \\
(1.836)\end{array}$ & $\begin{array}{c}1.317^{* * *} \\
(0.492)\end{array}$ & $\begin{array}{l}3.377 \\
(3.381)\end{array}$ & $\begin{array}{l}1.217 \\
(1.001)\end{array}$ \\
\hline T2 (SocSig) & $\begin{array}{l}1.659 \\
(0.828)\end{array}$ & $\begin{array}{l}0.506 \\
(0.499)\end{array}$ & $\begin{array}{l}2.738 \\
(2.699)\end{array}$ & $\begin{array}{l}1.007 \\
(0.986)\end{array}$ & $\begin{array}{l}1.260 \\
(0.550)\end{array}$ & $\begin{array}{l}0.231 \\
(0.437)\end{array}$ & $\begin{array}{l}1.667 \\
(1.341)\end{array}$ & $\begin{array}{l}0.511 \\
(0.805)\end{array}$ \\
\hline Belief & & & $\begin{array}{l}1.005 \\
(0.005)\end{array}$ & $\begin{array}{l}0.005 \\
(0.005)\end{array}$ & & & $\begin{array}{l}1.005 \\
(0.004)\end{array}$ & $\begin{array}{l}0.005 \\
(0.004)\end{array}$ \\
\hline \multicolumn{9}{|l|}{ Treatment $\times$ Belief } \\
\hline T1 (Reputation) × Belief & & & $\begin{array}{l}0.972^{*} \\
(0.015)\end{array}$ & $\begin{array}{c}-0.029^{*} \\
(0.015)\end{array}$ & & & $\begin{array}{l}1.002 \\
(0.010)\end{array}$ & $\begin{array}{l}0.002 \\
(0.010)\end{array}$ \\
\hline T2 (SocSig) $\times$ Belief & & & $\begin{array}{l}0.997 \\
(0.008)\end{array}$ & $\begin{array}{c}-0.003 \\
(0.008)\end{array}$ & & & $\begin{array}{l}0.998 \\
(0.007)\end{array}$ & $\begin{array}{l}-0.002 \\
(0.007)\end{array}$ \\
\hline Gender & & & $\begin{array}{l}3.826^{* *} \\
(2.472)\end{array}$ & $\begin{array}{l}1.342^{* *} \\
(0.646)\end{array}$ & & & $\begin{array}{l}1.065 \\
(0.517)\end{array}$ & $\begin{array}{l}0.063 \\
(0.485)\end{array}$ \\
\hline Risk & & & $\begin{array}{l}0.425^{* *} \\
(0.176)\end{array}$ & $\begin{array}{c}-0.856^{* *} \\
(0.413)\end{array}$ & & & $\begin{array}{l}1.270 \\
(0.314)\end{array}$ & $\begin{array}{l}0.239 \\
(0.247)\end{array}$ \\
\hline Self-Control & & & $\begin{array}{l}0.509^{* *} \\
(0.147)\end{array}$ & $\begin{array}{c}-0.676^{* *} \\
(0.289)\end{array}$ & & & $\begin{array}{l}1.422^{*} \\
(0.300)\end{array}$ & $\begin{array}{l}0.352^{*} \\
(0.211)\end{array}$ \\
\hline Charity Important & & & $\begin{array}{l}0.932 \\
(0.150)\end{array}$ & $\begin{array}{l}-0.070 \\
(0.161)\end{array}$ & & & $\begin{array}{l}1.195 \\
(0.144)\end{array}$ & $\begin{array}{l}0.178 \\
(0.121)\end{array}$ \\
\hline \multicolumn{9}{|l|}{ Charity } \\
\hline UNICEF & & & $\begin{array}{l}1.669 \\
(0.954)\end{array}$ & $\begin{array}{c}0.512 \\
(0.5713)\end{array}$ & & & $\begin{array}{l}0.432^{*} \\
(0.210)\end{array}$ & $\begin{array}{r}-0.840^{*} \\
(0.487)\end{array}$ \\
\hline WWF & & & $\begin{array}{l}0.515 \\
(0.386)\end{array}$ & $\begin{array}{r}-0.664 \\
(0.750)\end{array}$ & & & $\begin{array}{l}1.387 \\
(0.739)\end{array}$ & $\begin{array}{l}0.327 \\
(0.533)\end{array}$ \\
\hline $\begin{array}{l}\text { Post-estimation tests: } \\
\text { T1 vs. T2 }\end{array}$ & \multicolumn{2}{|c|}{$\mathrm{p}=0.011$} & \multicolumn{2}{|c|}{$p=0.724$} & \multicolumn{2}{|c|}{$p=0.025$} & \multicolumn{2}{|c|}{$p=0.499$} \\
\hline Observations & 126 & 126 & 126 & 126 & 126 & 126 & 126 & 126 \\
\hline
\end{tabular}

Table A2: Logistic Regression. Coefficients denote Odds Ratios (OR). Standard errors in parenthesis. $*^{* *},{ }^{*}$, and $*$ indicate significance at the $1 \%, 5 \%$, and $10 \%$ level, respectively. Gender $(1=$ male $) ;$ Belief (amount A beliefs about B's reimbursement decision); Risk (higher number = more risk-seeking, standardized measure); Self-Control (higher number = more self-control, standardized measure); Charity Important (higher number = higher preference for charities in general); Charity (higher number = higher preference for the respective charity, Doctors Without Borders are the reference category). 

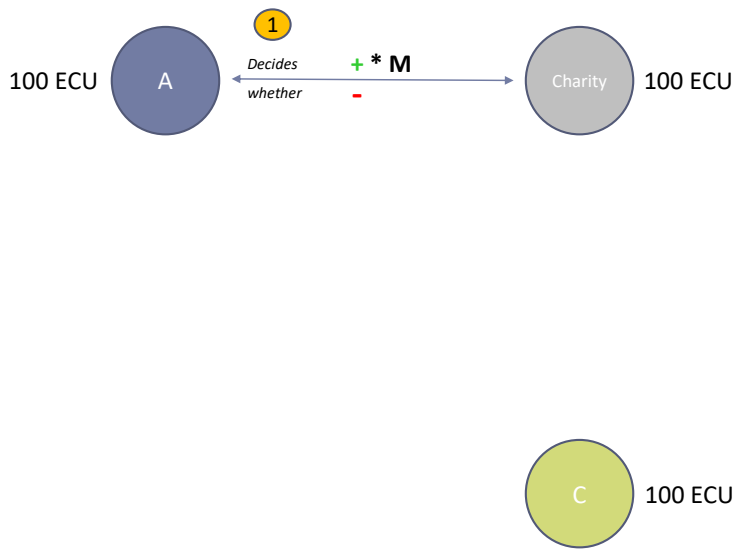

$M=$ Multiplicator
$Q=$ Order of decisions

Figure A.4: Design of Baseline condition on mTurk.

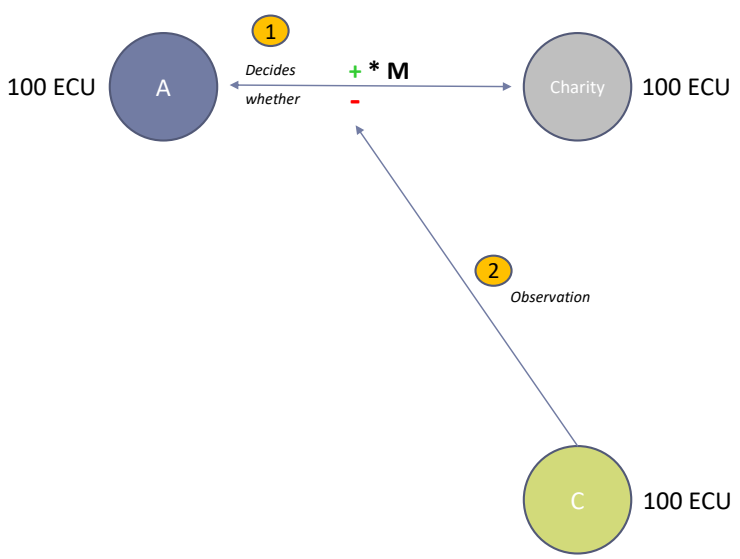

Figure A.5: Design of Treatment 2 (SocSig condition) on mTurk. 


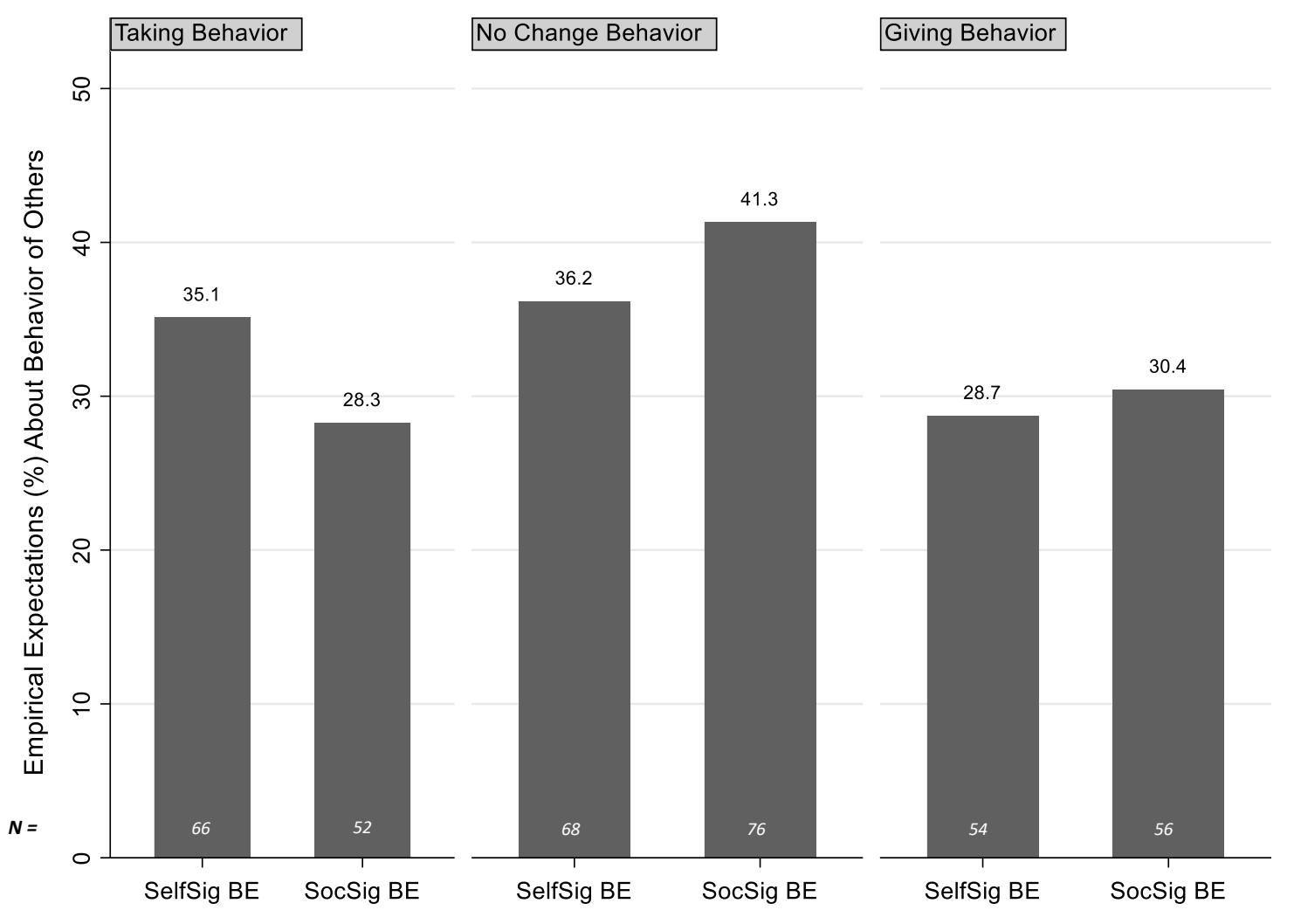

Figure A.6: Beliefs in SelfSig BE and SocSig BE conditions. None of the differences reaches significance. Taking behavior: MWU, $\mathrm{p}=0.156$; No Change Behavior: MWU, $\mathrm{p}=0.309$; Giving Behavior: MWU, $\mathrm{p}=$ 0.718 . 


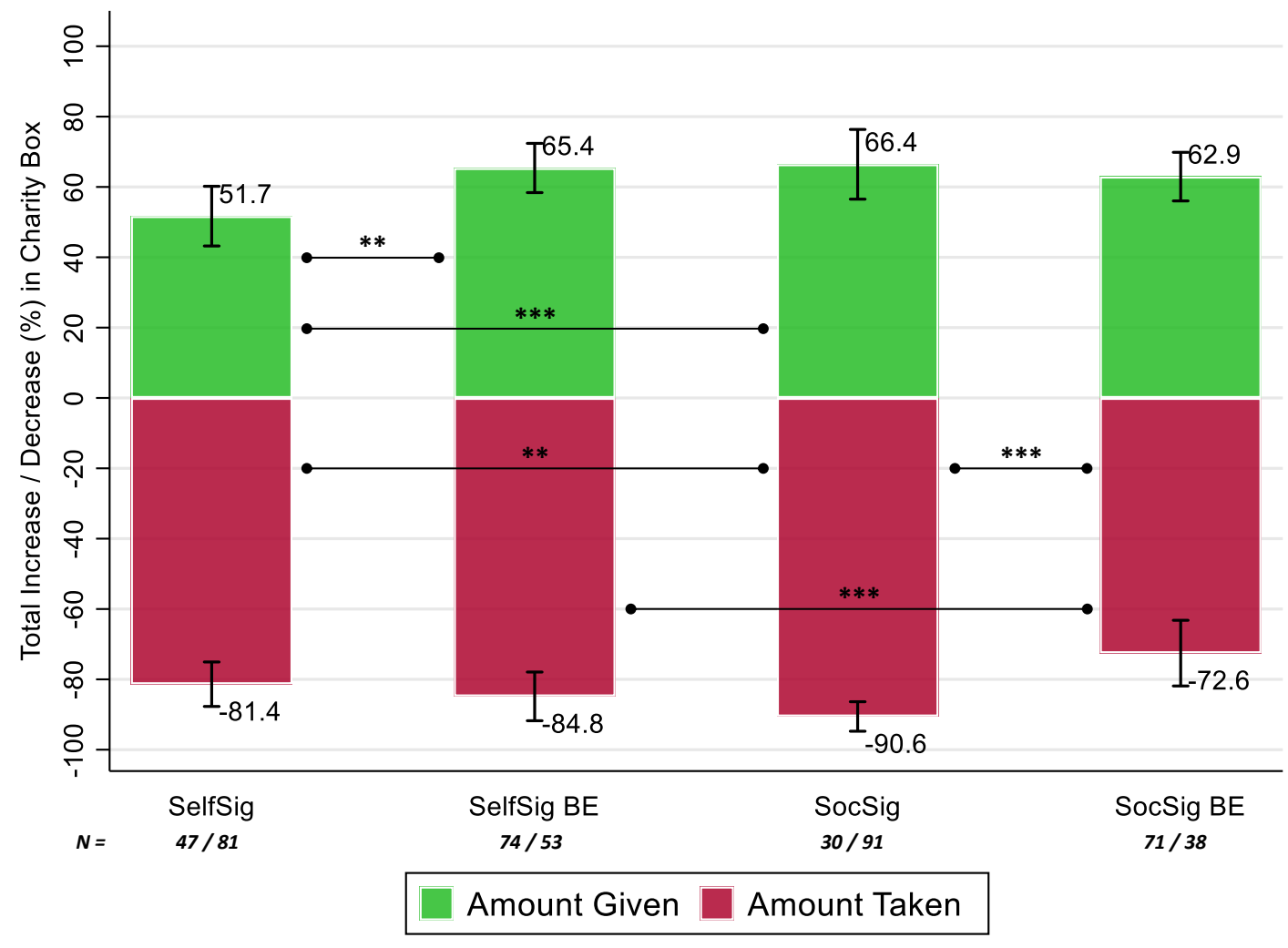

Figure A.7: Change in charity box (in monetary amounts) across treatments conditional on type of behavior. Observations per treatment and type of behavior are displayed at the bottom of each column in the topdown order. Horizontal lines with stars represent statistical significance at ${ }^{* * *} \mathrm{p}<0.01,{ }^{* *} \mathrm{p}<0.05$, and ${ }^{*}$ $\mathrm{p}<0.1$. Absence of horizontal implies lack of statistical significance at the conventional levels. Vertical lines represent $95 \%$ CIs. 


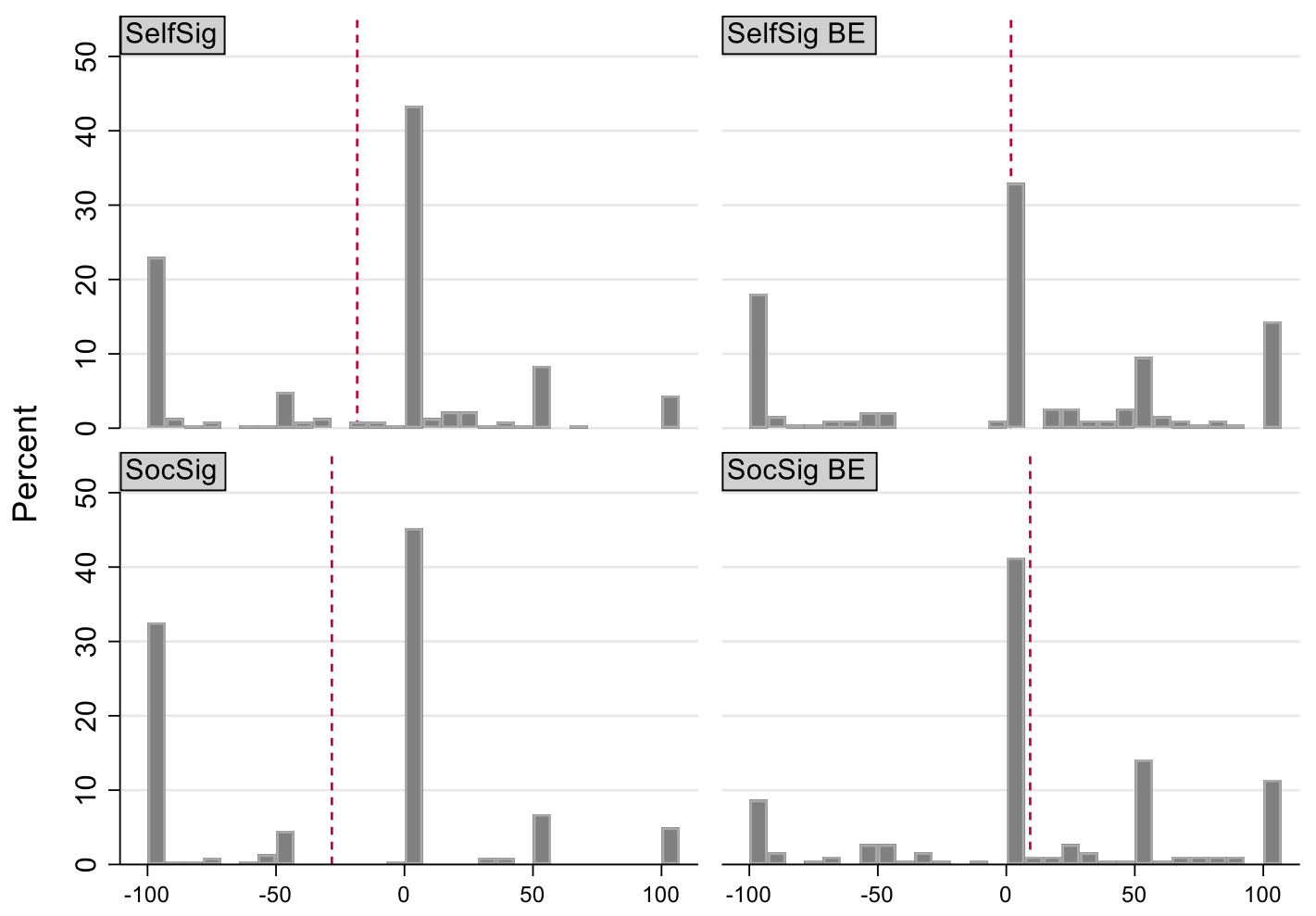

Figure A.8: Distribution of change in charity box (in monetary amounts) across treatments. 


\subsection{Instructions}

In what follows, we present the instructions used in the laboratory experiment.The instructions of the follow-up experiment on mTurk followed the same logic and were adjusted appropriately. Details are available upon request from the authors.

\section{Instructions}

- First of all, we would like to thank you very much for participating in this experiment. Please read the instructions carefully. The experiment will last for about 45-60 minutes.

- During the entire experiment, no communication is allowed. If there is something that you do not understand or if you have any questions, now or at some point during the experiment, please raise your hand and remain seated. One of our colleagues will come to you and answer your question.

- During the experiment, you have the possibility to earn money. The amount you will receive at the end of the session depends on how many "Taler" you earn during the experiment.

- At the end of the experiment, the amount of "Taler" that you have earned will be converted into real money at an exchange rate of 10 Taler $=1$ Euro.

- You will receive a show-up fee of 100 Taler with which you will play throughout the experiment. Depending on your role and your decisions, you will be able to make additional money. You will be paid anonymously at the end of the experiment.

\section{Procedure}

- The experiment consists of a questionnaire and decisions. The experiment will be played exactly once.

- There are 3 different types of roles in this experiment: A, B, and C. Player A moves first, after which Players B and C follow. In addition to this, a charity will be part of this experiment with which only Player A interacts.

- Each participant in this experiment is randomly assigned one of these three roles at the beginning of the experiment and remains in the same role throughout the experiment. No participant plays in more than one role.

- Each participant plays this experiment in groups of 3, each of which are in a different role. Hence, each group has exactly one participant in the role of A, B, and C, respectively. Each participant as well as the charity start with the exact same endowment of 100 Taler.

- The decision of Player A only affect the charity. The exact charitable organization will be randomly chosen from a list of 3 charities at the end of the experiment.

- The decision of Player B only affects the payoffs of Player A.

- Player $\mathrm{C}$ does not make any active decisions. 


\section{Player A's Role in Detail}

- A player in this role starts with his or her show-up fee of 100 Taler. The charitable organization with which this player interacts starts with 100 Taler as well.

- Player A can make one of the following decisions towards the charity exactly once:

1. To take money away from the charity and add to one's own account

2. To leave the equal split between him/her and the charity unaltered

3. To give money from one's own account to the charity (any amount given to charity will be doubled by the experimenter.

- The amount of money that is in the charity account at the end of the experiment will be doubled by the experimenter and donated to one of the following three charities: (1) Doctors Without Borders, (2) United Nations Children's Fund (UNICEF), or (3) World Wide Fund for Nature (WWF). The charity will be randomly chosen at the end of the experiment.

- To ensure the credibility of our claim, we will upload all donation receipts to our website in due time.

- Player A's decision towards the charity may or may not be observed by either Player B or Player C. This will be randomly determined once the experiment starts and announced on the screen.

\section{Player B's Role in Detail}

- A player in this role starts with his or her show-up fee of 100 Taler.

- In addition, this player is given the right to decide upon the distribution of an additional 100 Taler in a money box.

- This player decides whether and how much of the 100 Taler in this money box he/she wants to send to Player A. The mount sent will be doubled by the experimenter and added to Player's A account.

- Importantly, the money left in this money box, i.e. money that Player B decided not to send to Player A, cannot be retained by Player B. That is, Player B retains his/her original endowment of 100 Taler regardless of his/her decision of what to do with the 100 Taler in the money box.

\section{Player C's Role in Detail}

- A player in this role starts with his or her show-up fee of 100 Taler.

- Player $\mathrm{C}$ remains passive and does not engage in any active decision-making. 


\section{General Payoff Procedure}

- At the end of the experiment, exactly one group in this session that you partake is chosen at random.

Only the decisions of the members of this group are implemented. Based on this, both Player A and B, whose decisions are payoff-relevant, will be players from the same group.

- This means that the decision of exactly one Player $A$ in this experiment is going to determine the payoffs of the charitable organization.

- This also means that the decision of exactly one Player B will affect exactly one Player A's payoff.

- In this case, Player A can leave with a minimum of 0 Taler (if he/she decides to give all of the initial endowment to the charity) and a maximum of 400 Taler (if he/she decides to keep the own initial endowment (= 100 Taler), take all of the money from the charity (100 Taler), and receives all of the money from the charity by Player B ( $=2 * 100$ Taler)).

- Every other participant who is not part of the randomly chosen group will receive his/her initial endowment of 100 Taler regardless of his/her decisions. In those groups, no decisions towards the charity are payoff relevant. The charity will only be paid once by the group that is payoff relevant.

- Whether or not you are part of the payoff-relevant group will be revealed only at the very end of the experiment.

\section{Detailed Payoff Procedure}

If player ends up in the randomly chosen payoff-relevant group:

- Player A: (100 Taler initial endowment) +/- (Taler given to/taken from the charity) + (Taler received from Player B)

- $\quad$ Player B: 100 Taler

- Player C: 100 Taler

- Charity:

- If Player A decides to give money: 100 Taler $+2 *$ amount given by Player A

- If Player A decides to take money away: 100 Taler - amount taken by Player A

If player does not end up in the randomly chosen payoff-relevant group:

- Player A: 100 Taler

- Player B: 100 Taler

- Player C: 100 Taler

- Charity: 0 (decisions towards the charity not payoff relevant) 